\section{Guanabenz inhibits TLR9 signaling through a pathway that is independent of elF $2 \alpha$ dephosphorylation by the GADD34/PP1c complex}

\author{
Jessica Perego, ${ }^{1}$ Andreia Mendes, ${ }^{1,2}$ Clarisse Bourbon, ${ }^{1}$ Voahirana Camosseto, ${ }^{1,2}$ Alexis Combes, ${ }^{1}$ \\ Hong Liu, ${ }^{3}$ Thien-Phong Vu Manh, ${ }^{1}$ Alexandre Dalet, ${ }^{1}$ Lionel Chasson, ${ }^{1}$ Lionel Spinelli, ${ }^{1}$ \\ Nathalie Bardin, ${ }^{4,5}$ Laurent Chiche, ${ }^{6}$ Manuel A. S. Santos, ${ }^{2,7}$ Evelina Gatti, ${ }^{1,2,7 * \dagger}$ Philippe Pierre ${ }^{1,2,7 * \dagger}$
}

Endoplasmic reticulum (ER) stress triggers or amplifies inflammatory signals and cytokine production in immune cells. Upon the resolution of ER stress, the inducible phosphatase 1 cofactor GADD34 promotes the dephosphorylation of the initiation factor elF $2 \alpha$, thereby enabling protein translation to resume. Several aminoguanidine compounds, such as guanabenz, perturb the elF $2 \alpha$ phosphorylation-dephosphorylation cycle and protect different cell or tissue types from protein misfolding and degeneration. We investigated how pharmacological interference with the elF $2 \alpha$ pathway could be beneficial to treat autoinflammatory diseases dependent on proinflammatory cytokines and type I interferons (IFNs), the production of which is regulated by GADD34 in dendritic cells (DCs). In mouse and human DCs and B cells, guanabenz prevented the activation of Toll-like receptor 9 (TLR9) by CpG oligodeoxynucleotides or DNA-immunoglobulin complexes in endosomes. In vivo, guanabenz protected mice from CpG oligonucleotide-dependent cytokine shock and decreased autoimmune symptom severity in a chemically induced model of systemic lupus erythematosus. However, we found that guanabenz exerted its inhibitory effect independently of GADD34 activity on elF2 $\alpha$ and instead decreased the abundance of $\mathrm{CH} 25 \mathrm{H}$, a cholesterol hydroxylase linked to antiviral immunity. Our results therefore suggest that guanabenz and similar compounds could be used to treat type I IFN-dependent pathologies and that $\mathrm{CH} 25 \mathrm{H}$ could be a therapeutic target to control these diseases.

\section{INTRODUCTION}

The immunomodulating functions of dendritic cells (DCs), such as antigen presentation, are considerably enhanced after detection of cell damage-associated or pathogen-associated molecular patterns (PAMPs). Toll-like receptors (TLRs) have a major role in recognizing and initiating inflammatory or immune responses to PAMPs such as lipopolysaccharide (LPS) or nucleic acids (1). Most TLRs detect their ligand at the cell surface, except for TLR3, TLR7, TLR8, and TLR9, which are found in endosomes (2), where they are proteolytically activated and mediate nucleic acid recognition and signal transduction $(3,4)$. TLR7 and TLR9, whose ligands are, respectively, single-stranded RNA and DNA with unmethylated cytosine-phosphate-guanine (CpG) motifs $(5,6)$, are expressed in a restricted subset of immune cells, including B cells or plasmacytoid DCs (pDCs), which specialize in the production of type I interferon (IFN) (7). TLR9 and its DNA ligands must have access to specific endosome subsets to allow the recruitment and activation of the MyD88/IFN regulatory factor 7(IRF7)-dependent signaling pathway and to initiate type I IFN production (8). In pathological contexts, improper stimulation of endocytic TLRs by selfnucleic acids drives a feedforward positive inflammatory amplification loop, during which B cell-dependent secretion of autoantibodies and pDC activation by nucleic acid-immunoglobulin (Ig) complexes fuel the continuous release of pathogenic levels of type I IFN (7). TLR7and TLR9-expressing pDCs and B cells are therefore key cellular

\footnotetext{
${ }^{1}$ Aix Marseille Université, CNRS, INSERM, Centre d'Immunologie de Marseille-Luminy (CIML), 13008 Marseille, France. "International Associated Laboratory (LIA) CNRS "Mistra," 13008 Marseille, France. ${ }^{3}$ Sanofi, Cambridge, MA 02139, USA. "Laboratoire d'Immunologie, Hôpital de la Conception, 13005 Marseille, France. ${ }^{5}$ Aix Marseille Université, INSERM, VRCM, 13005 Marseille, France. ${ }^{6}$ Hôpital Européen, 13003 Marseille, France. ${ }^{7}$ Institute for Research in Biomedicine (iBiMED) and Aveiro Health Sciences Program University of Aveiro, 3810-193 Aveiro, Portugal.

*Corresponding author. Email: gatti@ciml.univ-mrs.fr (E.G.); pierre@ciml.univ-mrs.fr (P.P.) †These authors contributed equally to this work.
}

players in the establishment and progression of several type I IFNdependent diseases such as systemic lupus erythematosus (SLE) or Sjögren syndrome $(9,10)$.

The signaling cascades that regulate endoplasmic reticulum (ER) homeostasis and promote cell survival are collectively known as the integrated stress response (ISR) (11). Cross-talk between TLR signaling pathways and the ISR has been uncovered (12), in which the ISR provides an amplification signal that favors activation of nuclear factor $\kappa \mathrm{B}(\mathrm{NF}-\kappa \mathrm{B})$ and IRFs and that increases type I IFN or inflammatory cytokine production. Among the ISR signaling modules involved in this cross-talk, the phosphorylation of the $\alpha$ subunit of eukaryotic translation initiation factor $2(\mathrm{eIF} 2 \alpha)$ at $\operatorname{Ser}^{51}$ is particularly important $(13,14)$. This phosphorylation event, which can be executed by four different eIF2 kinases (PERK, PKR, GCN2, and HRI), inhibits the guanine nucleotide exchange factor eIF2B and results in reduced translation initiation and diminished production of newly synthesized proteins (15). Growth arrest and DNA damageinducible protein 34 (GADD34; also known as PPP1R15A) $(16,17)$ is a key ISR-inducible cofactor that promotes the dephosphorylation eIF $2 \alpha$ through its association with protein phosphatase 1 catalytic subunit (PP1c) and restores normal protein synthesis after the translational arrest initiated by the activation of kinases that phosphorylate eIF2 $\alpha$. GADD34 is required for the production of several inflammatory cytokines by double-stranded RNA (dsRNA)-activated DCs, including IFN- $\beta$ and interleukin-6 (IL-6) (14), and accordingly, GADD34-deficient mice cannot efficiently control viral infection $(13,14)$. GADD34 induction also attenuates LPS-induced sepsis and acute tissue injury in mouse by suppressing macrophage activation (18).

Pharmacological interference with GADD34 could be an attractive solution for inflammatory pathologies. Guanabenz [GBZ; 2-(2,6dichlorobenzylidene)hydrazinecarboximidamide] has been proposed to specifically inhibit GADD34 activity by disrupting its interaction 
with PP1c (19) and was introduced as a model compound to protect cells from lethal protein misfolding and treat diseases like amyotrophic lateral sclerosis (20). Originally, GBZ was developed as a small $\alpha 2$-adrenergic receptor agonist (trade name: Wytensin) that is well tolerated and received U.S. Food and Drug Administration approval for the treatment of hypertension (21). GBZ also has some anti-inflammatory properties in different pathological situations, including multiple sclerosis (22). The capacity of GBZ and of its derivative Sephin 1 to specifically inhibit the GADD34-holophosphatase complex has been challenged (23), although treated cells show increased eIF2 $\alpha$ phosphorylation and reduced protein synthesis activity. Given this ongoing controversy, we explored the impact of GBZ on TLR signaling relative to GADD34 activity using cells and animals expressing a nonfunctional form of the PPP1R15A gene $\left(G A D D 34^{\Delta \mathrm{C} / \Delta \mathrm{C}}\right)(24)$. Here, we confirmed that GADD34 inactivation inhibited the capacity of PAMP-activated DCs to produce type I IFN and proinflammatory cytokines in vitro and that pharmacological treatment with GBZ mostly recapitulated this genetic phenotype. However, GBZ also blocked TLR9-dependent activation by DNA in B cells and DCs independently of the presence of functional GADD34. These observations were confirmed in vivo, where GBZ protected both wild-type (WT) and $G A D D 34^{\Delta \mathrm{C} / \Delta \mathrm{C}}$ mice from the lethal cytokine shock caused by $\mathrm{CpG}$ oligodeoxynucleotide (ODN) injection after liver sensitization with D-galactosamine (D-GalN). GBZ injections also efficiently reduced circulating anti-nucleic acid antibody titer and lipogranuloma formation in the type I IFN-dependent tetramethylpentadecane (TMPD)-inducible SLE mouse model (25), suggesting that GBZ could potentially be used to treat type I IFN-mediated pathologies. Finally, we found that GBZ acts by reducing the expression of the cholesterol hydroxylase $\mathrm{CH} 25 \mathrm{H}$, revealing the importance of its enzymatic product 25hydroxycholesterol $(25-\mathrm{HC})$ for normal TLR9 intracellular sorting and signaling from endosomes during human $\mathrm{pDC}$ activation by CpG DNA.

\section{RESULTS}

\section{GBZ treatment partially phenocopies GADD34 genetic inactivation in DCs}

We have previously shown that IFN- $\beta$ and IL-6 production in response to the dsRNA mimic polyriboinosinic:polyribocytidylic acid [poly(I:C)] is defective in granulocytemacrophage colony-stimulating factor (GM-CSF)-induced bone marrow (BM)derived DCs from $G A D D 34^{\Delta \mathrm{C} / \Delta \mathrm{C}}$ mice (14). We investigated whether this observation could be extended to other DC subsets and other TLR ligands. WT and
$G A D D 34^{\Delta \mathrm{C} / \Delta \mathrm{C}} \mathrm{DCs}$ isolated directly from spleen or generated in vitro from BM progenitors, using either Flt3L- or GM-CSF-induced differentiation, were stimulated with LPS, poly(I:C), or CpG ODN. Flt3L-DCs are well suited for these in vitro experiments because they encompass all the main DC subsets (DC1, DC2, and pDCs) found in vivo and preferentially express TLR3, TLR4, or TLR9 (26). After poly(I:C) stimulation, Flt3L-DCs lacking functional GADD34 showed reduced IFN- $\beta$ and IL-6 production (Fig. 1, A and B), confirming the cytokine deficit observed in GADD $34^{\Delta \mathrm{C} / \Delta \mathrm{C}}$ GM-CSF DCs (Fig. 1, C and D). IFN- $\beta$ and IL-6 production in response to LPS was not affected by GADD34 deficiency in GM-CSF DCs. However, IFN- $\beta$ secretion was augmented whereas IL-6 secretion was decreased in GADD $34^{\Delta \mathrm{C} / \Delta \mathrm{C}}$ Flt3L-DCs (Fig. 1, A to D). When compared to in vitro-generated cells, $\mathrm{CD} 11 \mathrm{c}^{+} \mathrm{DCs}$ directly isolated from mouse spleen were also sensitive to GADD34 inactivation (Fig. 1, E and F). However, IL-6 production was less effectively
A

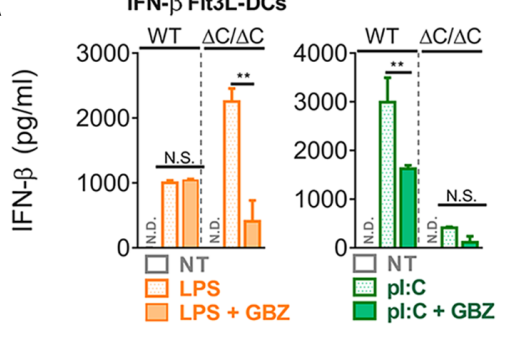

B

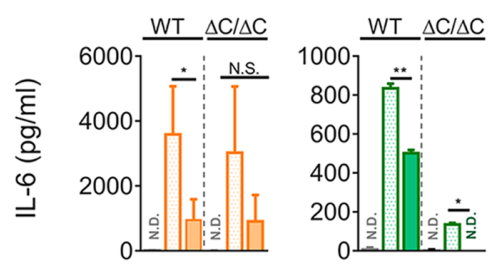

C

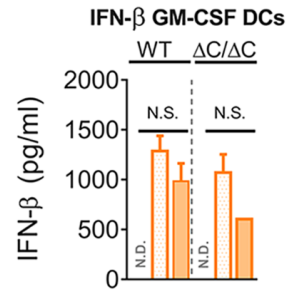

E

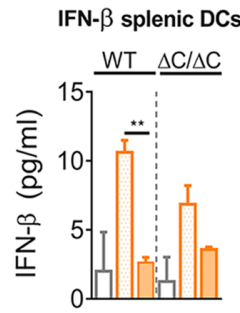

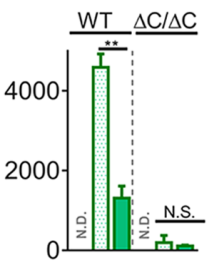

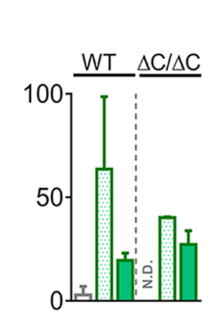

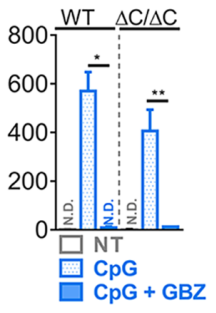

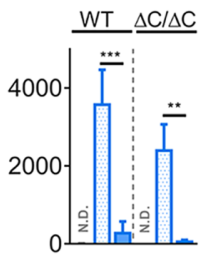

D
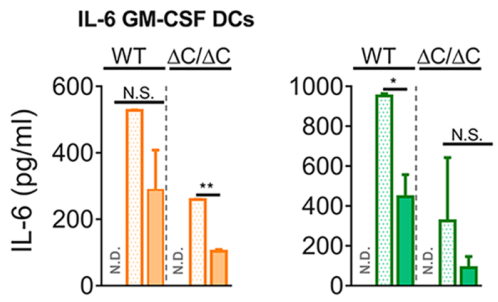

$\mathbf{F}$
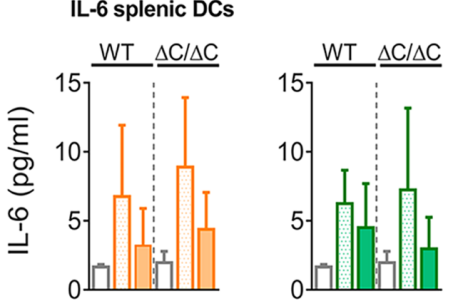

Fig. 1. GBZ mimics GADD34 inactivation and impairs TLR3 and TLR9 signaling. (A to F) Bone marrow-derived Flt3L-DCs (dendritic cells) (A and B), bone marrow-derived granulocyte-macrophage colony-stimulating factor (GM-CSF) DCs (C and D), and splenic DCs (E and F) from wild-type (WT) or GADD34 ${ }^{\Delta C / \Delta C}(\Delta C / \Delta C)$ mice were stimulated for 6 hours with lipopolysaccharide (LPS) (100 ng/ml; from Escherichia coli), low-molecular weight (LMW) poly(l:C) (pl:C; $10 \mu \mathrm{g} / \mathrm{ml})$, or $1 \mu \mathrm{M}$ ODN 1585. NT, nontreated. Guanabenz (GBZ) was added at $50 \mu \mathrm{M}$. The concentrations of secreted interferon- $\beta$ (IFN- $\beta$ ) ( $A, C$, and E) or interleukin-6 (IL-6) (B, D, and F) were measured by enzyme-linked immunosorbent assay (ELISA). Statistical significance was assigned using two-tailed $t$ test on at least three independent experiments $\left({ }^{*} P<0.05 ;{ }^{* *} P<\right.$ $\left.0.005 ;{ }^{* * *} P<0.0005\right)$. N.D., not detected; N.S., not significant. 
inhibited, suggesting that the effect varies according to the cell type studied and the stimulation or differentiation conditions used.

We next tested the effect of treating DCs with GBZ, a small compound that reportedly inhibits the GADD34/PP1c interaction (19). For IL-6 production, GBZ had an effect similar to that of GADD34 inactivation. However, we noticed that GBZ more strongly inhibited IFN- $\beta$ production in response to TLR9 stimulation than did GADD34 genetic inactivation (Fig. 1, A to F). This effect was particularly acute upon CpG ODN stimulation of GADD $34^{\Delta \mathrm{C} / \Delta \mathrm{C}}$ Flt3L-DCs, which were incapable of producing IFN- $\beta$ or IL- 6 upon GBZ treatment, which also synergized with the lack of functional GADD34 (Fig. 1, A and B). These additive effects also suggested that GBZ interferes with proteostasis independently of GADD34/PP1c binding, as has been proposed by Crespillo-Casado and collaborators (23).

\section{GBZ inhibits DC activation by poly(l:C) and CpG ODN}

We decided to further investigate the strong inhibition of TLR3 and TLR9 by GBZ. Among mouse DC subsets, TLR3 and TLR9 are most abundant in $\mathrm{CD}^{+}{ }^{+}$-like conventional DCs (cDC1) and in pDCs $(26,27)$.

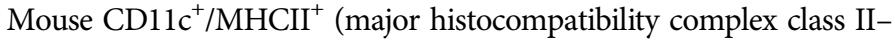
positive) DCs from Flt3L-treated BM cultures were sorted as $\mathrm{CDC1}$

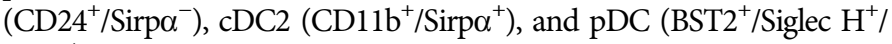
$\mathrm{B} 220^{+}$) (Fig. 2A). Sorted TLR3-expressing $\mathrm{CDC1}$ were activated with low-molecular weight (LMW) poly(I:C), and TLR9-expressing pDCs were stimulated with $\mathrm{CpG}-\mathrm{A}$ ODN. In both cases, GBZ treatment nearly abrogated cytokine production and IFN- $\beta$ and IL- 6 secretion by $\mathrm{pDCs}$ in particular (Fig. 2B) without affecting cell viability. GBZ also completely inhibited the transcriptional response to $\mathrm{CpG}$ ODN, as judged by the loss of the expression of key genes in pDCs, including IFNA4, TNF, ISG15, and $I L 12 B$, as monitored by quantitative polymerase chain reaction (qPCR) (Fig. 2C), and the lack of surface CD86 and CD69 up-regulation after mouse primary $B$ cell activation (fig. S1A).

We next evaluated GBZ-mediated inhibition on NF- $\kappa \mathrm{B}$ signaling by monitoring secreted alkaline phosphatase (SEAP) reporter levels in human embryonic kidney (HEK)-293 cells expressing various human TLRs (Fig. 3A). As expected, GBZ treatment inhibited TLR3-, TLR7-, and TLR9-dependent activation of the SEAP reporter, but not of that by TLR4. We next treated freshly isolated $\mathrm{BDCA} 4^{+} / \mathrm{CD} 123^{+}$ human primary blood $\mathrm{pDCs}$ activated with either CpG-A- or DNA-IC-containing serum from lupus patients (Fig. 3B). GBZ prevented the production of type I IFN and tumor necrosis factor- $\alpha$ (TNF- $\alpha$ ) by stimulated human pDCs independently of the ligands used. Similarly, GBZ inhibited TNF- $\alpha$ secretion and cytokine expression at the mRNA level in the human CAL1 pDC line (Fig. 3C) (28) and in primary human B cells (fig. S1B). The functionality of the TLR9 transduction pathway was next evaluated by using flow cytometry to detect the phosphorylation of 40 S ribosomal protein S6, an early signaling event downstream of TLR activation by LPS or viruses $(29,30)$. GBZ-treated CAL-1 and human B cells both displayed a reduction in S6 phosphorylation that was normally induced after CpG exposure (Fig. 3D and fig. S1C), suggesting that GBZ inhibits an upstream step in the TLR9 signal transduction pathway.

\section{GBZ protects mice from CpG ODN-induced cytokine shock independently of GADD34}

In addition to its hypotensive indications in humans, the therapeutic potential of GBZ for misfolded protein stress-associated diseases has been tested in mice (22), primarily in neurodegenerative diseases characterized by both neuronal degeneration and inflammation. Despite conflicting results $(22,31,32)$, these mouse experiments have yielded important pharmacokinetics data on GBZ, including a plasma half-life of 1.8 hours and a spinal cord accumulation of about $7 \mu \mathrm{M}$ several hours after a single intraperitoneal bolus injection of $2 \mathrm{mg} / \mathrm{kg}$. We decided to test GBZ-mediated inhibition of TLR9 by injecting CpG ODN into mice after liver sensitization with $\mathrm{D}-\mathrm{GalN}$. Less than $20 \%$ of CpG-injected animals survived 48 hours after injection (Fig. 4A). This survival rate was not substantially changed by coinjection with clonidine [ $N$-(2,6-dichlorophenyl)-4,5-dihydro- $1 H$-imidazol-2-amine], a different $\alpha 2$-adrenergic receptor agonist without GADD34 inhibitory
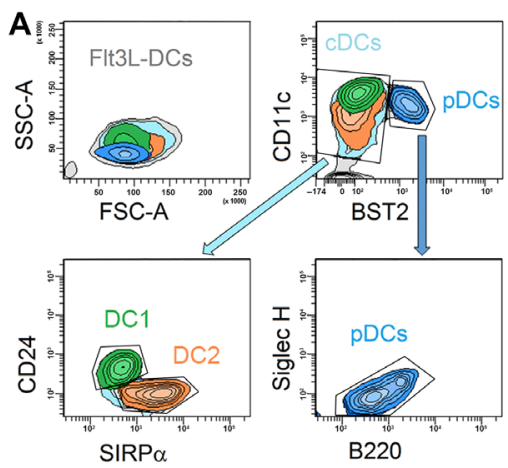

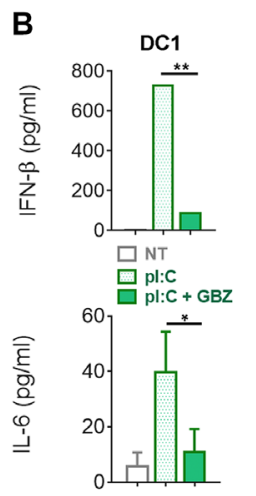

C
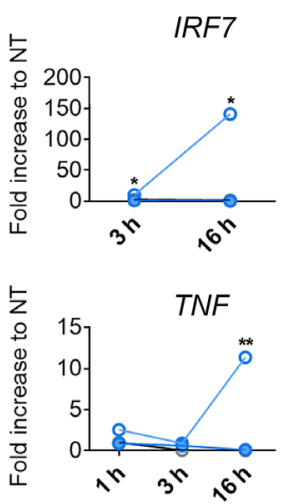

ISG15
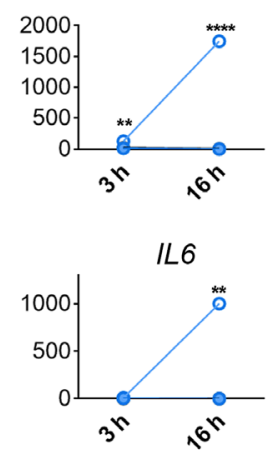

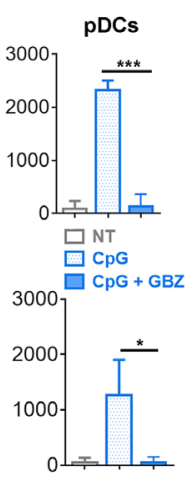

IFNA4
Fig. 2. GBZ inhibits TLR9 activation in mouse FIt3L-DCs. (A) Sorting strategy for bone marrow-derived Flt3LDCs. (B) IFN- $\beta$ and IL-6 secretion in sorted DC1 and plasmacytoid DCs (pDCs) activated for 6 hours with LMW poly(l:C) $(10 \mu \mathrm{g} / \mathrm{ml})$ or $1 \mu \mathrm{M}$ ODN 1585 , respectively. GBZ was added at $50 \mu \mathrm{M}$. (C) Sorted pDCs were also analyzed for the transcriptional induction of genes encoding ISGs (IRF7 and ISG15) and cytokines (IFNA4, IL12B, IL6, and TNF) at different time points. Data are represented as fold increase compared to untreated pDCs. Statistical significance was assigned using two-tailed $t$ test on at least $n=3$ independent experiments $\left({ }^{*} P<0.05 ;{ }^{* *} P<0.005 ;{ }^{* *} P<0.0005 ;{ }^{* * *} P<0.0001\right.$ ). 
A

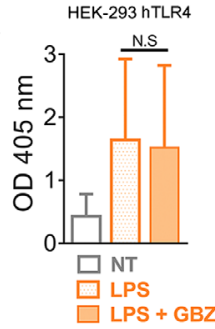

HEK-293 hTLR9

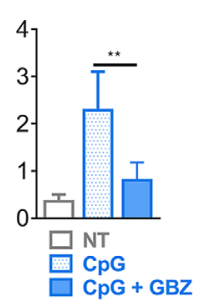

B

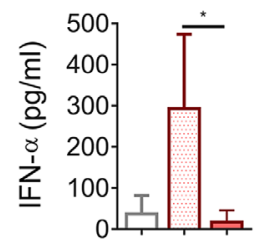

C
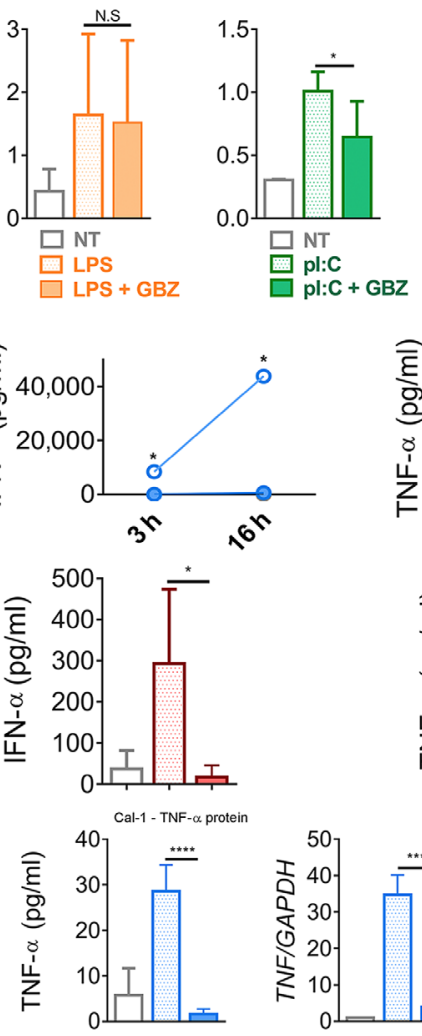

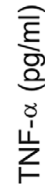

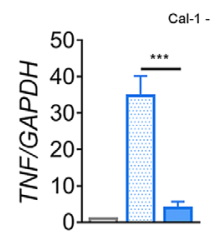

Cal-1 - mRNA lever
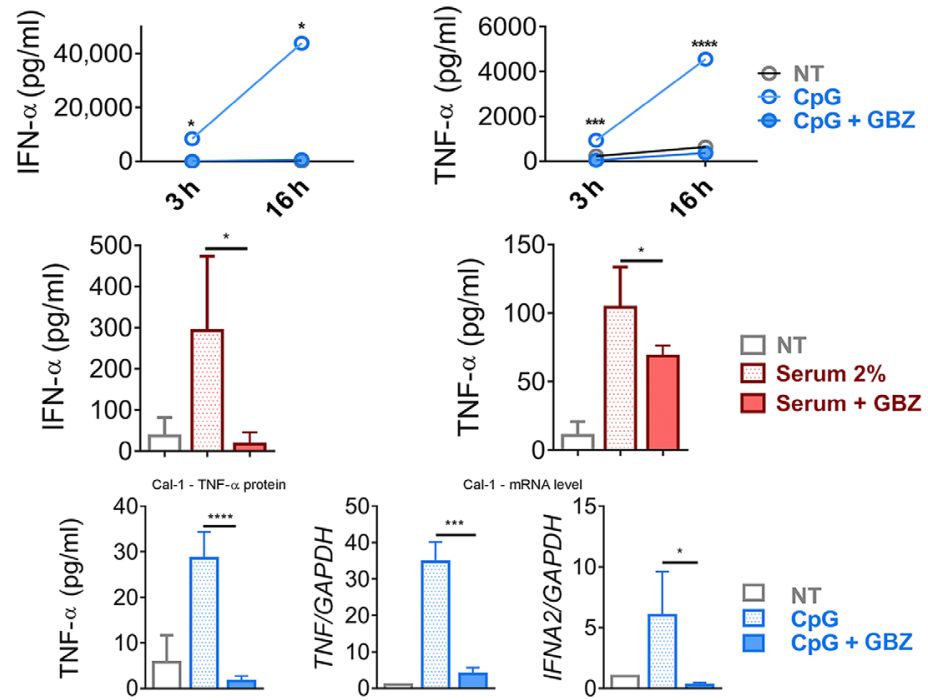

P-S6 Cal-1

D

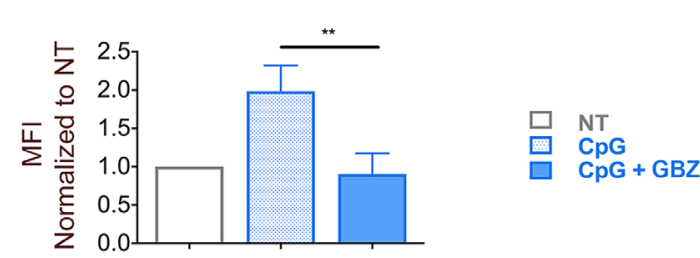

$\square$ CpG

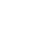

(1)

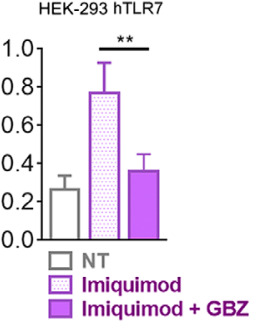

D

Fig. 3. GBZ impairs TLR9 signaling in human cells. (A) Human Toll-like receptor 4 (hTLR4), hTLR3, hTLR9, and hTLR7 reporters expressed in HEK-Blue cells were activated with LPS (100 ng/ml), LMW poly(l:C) $(10 \mu \mathrm{g} / \mathrm{ml}), 2.5 \mu \mathrm{M}$ ODN 2006, or imiquimod $(5 \mu \mathrm{g} / \mathrm{ml})$, respectively. HEK-293, human embryonic kidney 293 cells; OD $405 \mathrm{~nm}$, optical density at $405 \mathrm{~nm}$. GBZ was added at $50 \mu \mathrm{M}$. TLR activity was measured indirectly through secreted alkaline phosphatase (SEAP) activity as absorbance at $405 \mathrm{~nm}$. (B) Human primary pDCs were isolated from blood and activated either with $3 \mu \mathrm{M}$ ODN 2216 or $2 \%$ serum from lupus patients. GBZ was added at $50 \mu \mathrm{M}$. Secreted IFN- $\alpha$ and tumor necrosis factor- $\alpha$ (TNF- $\alpha$ ) were measured at the indicated time points or at 16 hours. (C) CAL-1 cells were stimulated with $3 \mu \mathrm{M}$ ODN 2216. GBZ was added at $50 \mu \mathrm{M}$. Secreted TNF- $\alpha$ was measured 3 hours after activation. Gene expression of TNF and IFNA2 were measured by quantitative polymerase chain reaction (qPCR) and normalized on untreated cells. (D) Mean fluorescence intensity (MFI) for phospho-ribosomal protein S6 (P-S6) detected by intracellular phospho-flow cytometry in CpG-A-activated CAL-1 cells treated or not with GBZ. Data of three experiments were normalized to those from nontreated cells. Statistical significance was assigned using two-tailed $t$ test on at least three independent experiments $\left({ }^{*} P<0.05 ;{ }^{* *} P<0.005 ;{ }^{* * *} P<0.0005 ;{ }^{* * *} P<0.0001\right)$.

activity (33). Clonidine was therefore used as a control compound throughout our study to evaluate the impact of the inhibition of $\alpha 2$ adrenergic receptor signaling and hypotension on the general toxicity induced by D-GalN and CpG injections. Coinjection of GBZ with CpG increased survival up to $70 \%$. However, $G A D D 34^{\Delta \mathrm{C} / \Delta \mathrm{C}}$ mice were as sensitive as WT animals to D-GalN and CpG injections and were also protected from death by GBZ treatment (Fig. 4B). Therefore, GBZ inhibits TLR9 in vivo independently of GADD34, although with decreased efficiency $(-28 \%)$, suggesting cross-talk between GBZ-induced proteos- tasis and GADD34 inactivation that favors survival in this pathological model.

In WT animals, GBZ treatment decreased circulating TNF- $\alpha$ and IL- 6 plasma concentrations (Fig. 4C). Although circulating type I IFN remained undetectable, production of the anti-inflammatory cytokine IL-10 was increased, suggesting that GBZ could exert protective effects by reinforcing secondary anti-inflammatory responses in vivo (Fig. 4C). Although much less efficient than GBZ, clonidine had some inhibitory effect on TNF- $\alpha$ and IL-6 production after 1 hour, but this inhibition was not observed after 3 hours (Fig. 4C), suggesting that hypotension could contribute to reduce the diffusion of inflammatory cytokines for a short period after injection. In the D-GalN model, LPS-induced lethality is triggered by a caspase-dependent fulminant apoptotic hepatitis induced by TNF- $\alpha$ overproduction and not directly from the systemic inflammatory response (34). However, in this model of CpG-induced lethality, liver examination and histological scores indicated that GBZ did not increase hepatic cell survival (Fig. 4D) and that its activity was most likely exerted through the inhibition of proinflammatory cytokine release by immune cells and not by hepatocytes.

\section{GBZ protects mouse from TMPD-induced autoimmunity}

TMPD (pristane) intraperitoneal injection induces an SLE-like disease in mice (25). In this pathological model, glomerulonephritis and autoantibody production strictly depend on signaling through the IFN- $\alpha / \beta$ receptor (IFNAR) and the formation of "lipogranulomas," which represent a chronic inflammatory response to TMPD and are the sites of autoantibody production $(25,35)$. Monocytes are recruited to the inflamed peritoneal cavity where they are activated by endogenous TLR7 and, potentially, TLR9 ligands and are the major sources of type I IFN in this model, which, after a period of 3 to 4 months, results in different autoimmune manifestations specific to the mouse genetic background $(25,36,37)$. The TMPD-inducible SLE model appears, therefore, to be particularly suitable for testing GBZ inhibitory activity on endosomal TLRs in vivo, because it is inducible and type I IFN-dependent and mimics some human SLE features (38). We modified the original protocol of TMPD-induced SLE (36) by adding an intraperitoneal injection of CpG ODN to boost TLR9dependent activation and reinforce type I IFN production that should be counteracted by GBZ treatment (Fig. 5A). CpG injection alone had 


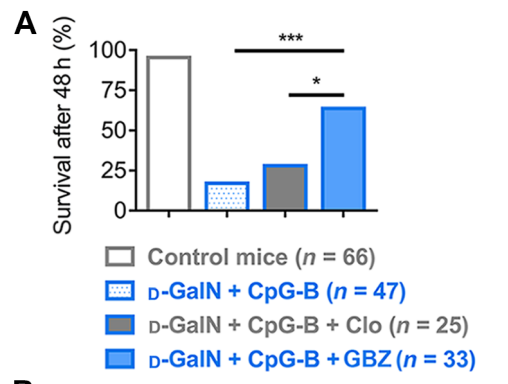

B
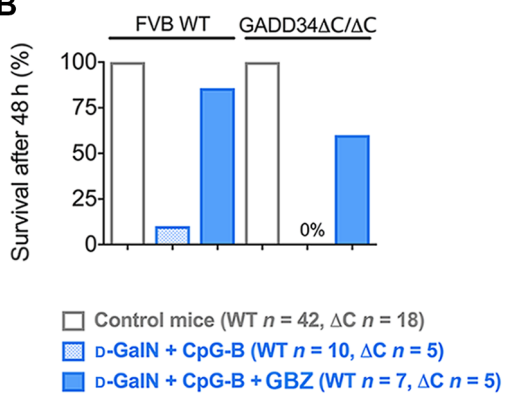

C
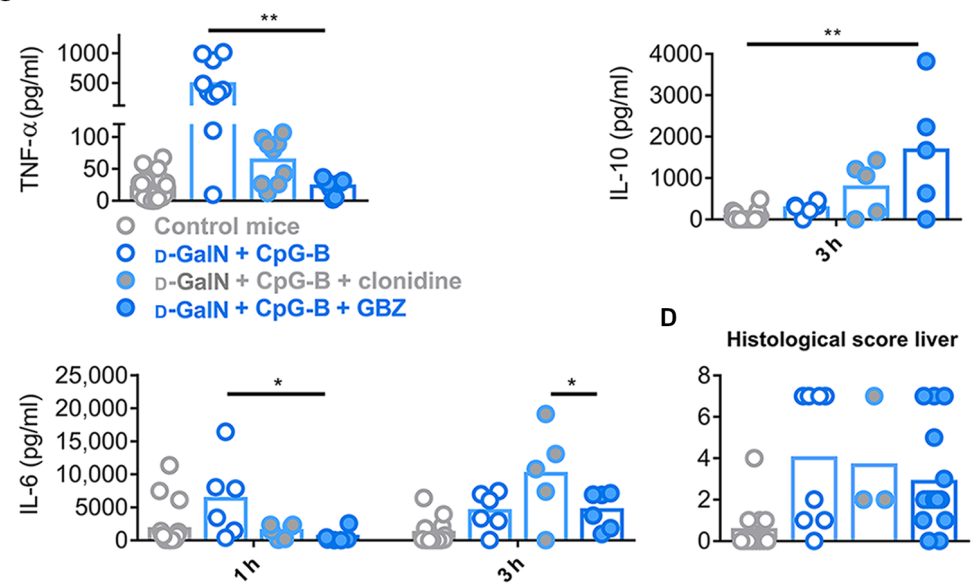

Fig. 4. GBZ rescues mice from TLR9-dependent cytokines shock. (A and B) WT (A) and GADD34 ${ }^{\Delta C / \triangle C}$ (B) mice were injected with D-GalN (20 mg per mouse), ODN 1826 or phosphate-buffered saline (PBS) for control mice $(50 \mu \mathrm{g} / 20 \mathrm{~g})$, and GBZ or clonidine (Clo; $2 \mathrm{mg} / \mathrm{kg}$ ). Survival is represented as total percentage of survival after 48 hours (left) or in a Kaplan-Meier plot (right). (C) The concentrations of circulating TNF- $\alpha$, IL-10, and IL- 6 were measured at 1 and/or 3 hours. (D) Liver tissue damage (histological score) was determined in a blinded fashion by a pathologist. Statistical significance was assigned on sample comparison by a one-way analysis of variance (ANOVA), followed by Tukey range test, and on the survival curve using log-rank test, followed by Benjamini-Yekutieli correction ${ }^{*} P<0.05$; ${ }^{* *} P<0.005$; ${ }^{* *} P<$ 0.0005.). $n$ values in the figure indicate the number of mice.

a comparable effect as TMPD on the recruitment of different inflammatory cell populations, in particular $\mathrm{Ly}_{6 \mathrm{G}}{ }^{+}$neutrophils and $\mathrm{Ly} 6 \mathrm{C}^{+}$ monocytes, which were enriched in peritoneal exudate cells (PECs) at day 14 (fig. S2A), suggesting that the two treatments could synergize, as demonstrated by the increased type I IFN signature observed immediately after $\mathrm{CpG}$ injection (fig. S2B).

Flow cytometry analysis of PECs from TMPD/CpG-injected C57BL/6 mice revealed that, as expected, TMPD/CpG treatment decreased peritoneal B cell numbers $\left(\mathrm{CD} 11 \mathrm{~b}^{\mathrm{dim} /-} / \mathrm{CD} 19^{+}\right)$while concomitantly increasing the recruitment of neutrophils $\left(\mathrm{Ly}_{6} \mathrm{G}^{+} / \mathrm{CD} 11 \mathrm{~b}^{+}\right)$and inflammatory monocytes (Ly6C ${ }^{+}$) (Fig. 5, B and C). GBZ injections did not prevent immune cell migration into or from the peritoneal cavity, indicating that the drug did not affect this key step in TMPD- induced pathology (Fig. 5, B and C). We next attempted to measure IFN-stimulated gene (ISG) expression in peritoneal cells of two different mouse cohorts (Fig. 5D). The expression of TNF- $\alpha$ and of type I IFN-inducible ISG15 and $\mathrm{CH} 25 \mathrm{H}$ genes were induced in PECs isolated from TMPDand $\mathrm{CpG}$-injected mice compared to control littermates. These transcriptional responses, indicative of both ongoing inflammation and type I IFN production, were inhibited by recurrent GBZ injections (Fig. 5D). TMPD-treated C57BL/6 mice are biased to generate anti-ribonucleoprotein or RNA autoantibodies rather than antiDNA autoantibodies in the long term (25). Titers of circulating antinuclear and antiRNA Ig plasma concentration in response to TMPD injection were substantially lower in GBZ-treated mice than in animals injected with TMPD and CpG only (Fig. 5E). In agreement with these data, the peritoneal cavity of GBZ-treated mice contained considerably fewer plasma cell-containing lipogranulomas, explaining the lower circulating concentration of autoantibodies and confirming the inhibitory activity of GBZ on the activity of endocytic TLRs (Fig. 5D). As expected in C57BL/6 mice (25), and despite additional CpG ODN treatment, we could not induce sufficient glomerulonephritis overall to observe significant differences in the levels of Ig complex deposits in the kidneys of control and GBZtreated animals. Together, these data support the efficacy of GBZ as an inhibitor of nucleic acid activation of TLRs in vivo.

\section{$\mathrm{CH} 25 \mathrm{H}$ expression is down-modulated by GBZ}

To identify the GBZ-mediated molecular mechanisms that inhibit TLR signaling, we tested various hypotheses. To test for the unlikely role for $\alpha 2$-adrenergic receptor agonism in this process, we assessed the effect of clonidine on TLR9 inhibition in vitro. In contrast to GBZ, clonidine did not attenuate the increase in CD86 and CD69 in CpG-stimulated splenic B cells (fig. S1A). These results ruled out a major role for $\alpha 2$-adrenergic receptor activation in controlling TLR9 signaling. Because of the importance of endosomal acidification and proteolysis for endocytic TLR activation, we next tested whether GBZ interferes with these basic functions, as previously observed for chloroquine and bafilomycin, two inhibitors of endosome acidification and endocytic TLR activity (fig. S3, A and B). Monitoring of endosome acidification in HEK-293 cells by flow cytometry and fluorescein isothiocyanate fluorescence quenching assay (39) revealed that GBZ did not affect acidification, unlike the positive control bafilomycin (fig. S3A). As an alternative measurement of endosomal proteolysis, we assessed the cathepsin-dependent 


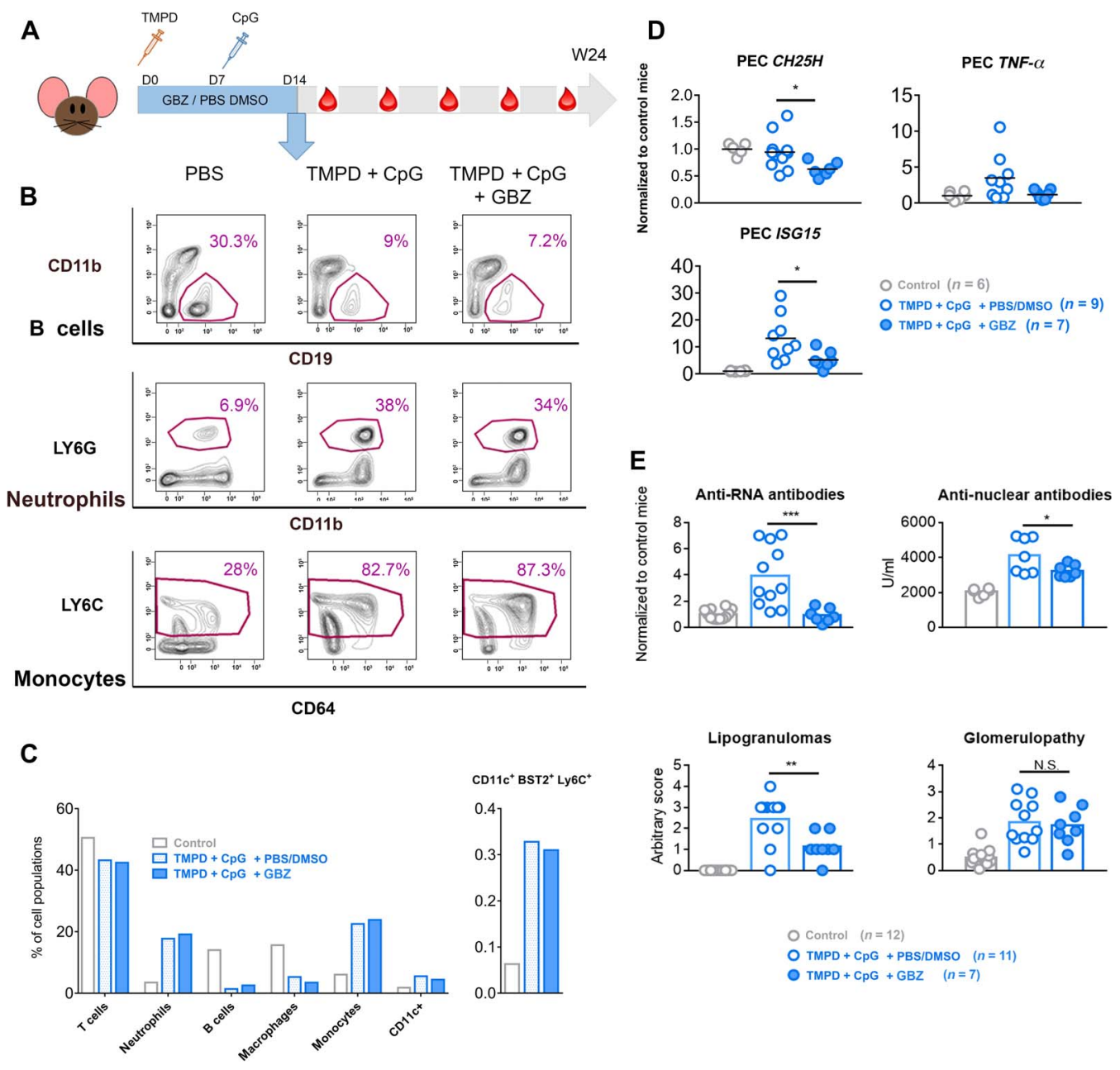

Fig. 5. GBZ decreases the severity lupus-like symptoms in the pristane injection model. (A) The experimental protocol: Mice were injected at day 0 (D0) with PBS or $500 \mu \mathrm{l}$ of tetramethylpentadecane (TMPD) and then injected every 2 days for 2 weeks with PBS/dimethyl sulfoxide (DMSO) or GBZ (2 mg/kg). At day 7 , mice were injected with ODN $1585(50 \mu \mathrm{g} / 20 \mathrm{~g})$. Blood was collected monthly to determine the circulating autoantibody level. Mice were sacrificed at week 24 (W24) after disease induction. (B and C) Flow cytometry analysis of peritoneal exudate cell (PEC) populations at day 14. (D) Mice were sacrificed at week 24, and gene expression of IFNstimulated genes (ISGs) and cytokines in PECs was determined by qPCR. Statistical significance was assigned using two-tailed Student's $t$ test $(* P<0.05)$. (E) Level of circulating anti-RNA antibodies (normalized to control mice), antinuclear antibodies (arbitrary units), the presence of lipogranulomas in the peritoneal cavity (arbitrary score), and glomerulopathy (histological score was determined in a blinded fashion by a pathologist) at week 24 . Statistical significance was assigned by a one-way ANOVA, followed by Tukey range test $\left({ }^{*} P<0.05 ;{ }^{* *} P<0.005 ;{ }^{* *} P<0.0005\right) . n$ values in the figure indicate the number of mice.

degradation of the MHCII-associated invariant chain (also known as Ii or CD71), which occurs rapidly in mouse $\mathrm{A} 20 \mathrm{~B}$ cells (40). In contrast to chloroquine, which caused accumulation of the characteristic Ii proteolytic intermediates p10 and p22 (fig. S3B), GBZ did not affect Ii endosomal degradation even with prolonged treatment. We also asked whether the increase in eIF2 $\alpha$ phosphorylation triggered by GBZ in mouse DCs (fig. S3C) could inhibit protein synthesis and influence directly cytokine production. We therefore optimized the puromycylation procedure "SUNSET" to quantify protein synthesis by intracellular flow cytometry (41). As expected from our previous work on GADD $34^{\Delta \mathrm{C} / \Delta \mathrm{C}}$ DCs (14), GBZ did not alter mRNA translation in CpG-activated pDCs (fig. S3D) and was therefore unlikely to affect TLR signaling and cytokine production by directly inhibiting protein synthesis.

In the absence of obvious mechanistic clues explaining the inhibitory effect of GBZ on TLR signaling, we initiated an unbiased comparative microarray-based genomic analysis on purified GM-CSF CD11c ${ }^{+}$DCs, stimulated with Proteus mirabilis extract (a TLR4 ligand) or poly(I:C) (a TLR3 ligand) in the presence or absence of GBZ. We used these experimental conditions instead of stimulating with CpG ODN, because they trigger substantial, but less extreme, responses to GBZ treatment than does CpG exposure. Thus, a transcriptomic analysis performed in these samples was more likely to reveal subtle gene expression differences that would likely be difficult to detect upon the complete shutdown of TLR9 signaling and type I IFN secondary responses induced by GBZ. Principal components analysis showed a close proximity of replicates without a clear partitioning of GBZ-treated cells from activated controls (Fig. 6A). Reflecting this analysis, only a few genes, identified among those with the greatest increase in expression ( $>10$-fold change), showed reduced expression upon GBZ treatment (table S1). In addition to the genes encoding type I IFNs and several ISGs, cholesterol 25 hydroxylase $(\mathrm{CH} 25 \mathrm{H})$ expression was the most significantly affected by GBZ upon $P$. mirabilis and poly(I:C) stimulation (60 and $90 \%$ of inhibition, respectively). Ch25h is induced by type I IFNs downstream of TLR3 or TLR4 activation (42), and the 
A

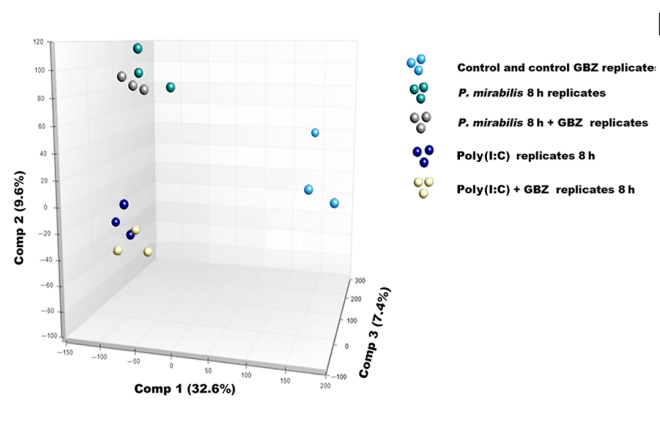

C

\begin{tabular}{|c|c|c|}
\hline Gene symbol & $\mathrm{Fc} \mathrm{pl:C}$ & Fc pl:C+ GBZ \\
\hline AACS & -2.813 & na \\
\hline MVK & -2.348 & na \\
\hline MVD & -2.287 & na \\
\hline SQLE & -3.980 & -2.699 \\
\hline LSS & -3.002 & na \\
\hline CYP51A1 & -3.296 & na \\
\hline TM7SF2 & -2.217 & na \\
\hline NSDHL & -2.330 & na \\
\hline HSD17B10 & -3.067 & -2307 \\
\hline HSD17B7 & -2.246 & na \\
\hline$S C 5 D$ & -2.716 & -2.024 \\
\hline DHCR24 & -3.307 & -2.128 \\
\hline DHCR7 & -5.874 & -2.095 \\
\hline MYLIP & 3.022 & na \\
\hline$A B C G 1$ & 2.041 & па \\
\hline
\end{tabular}

D

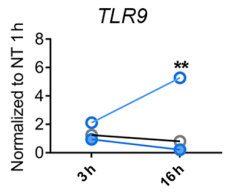

$\mathrm{CH} 25 \mathrm{H}$

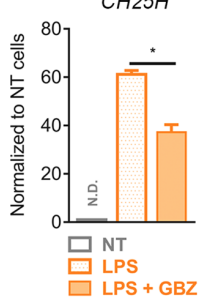

B terestcon

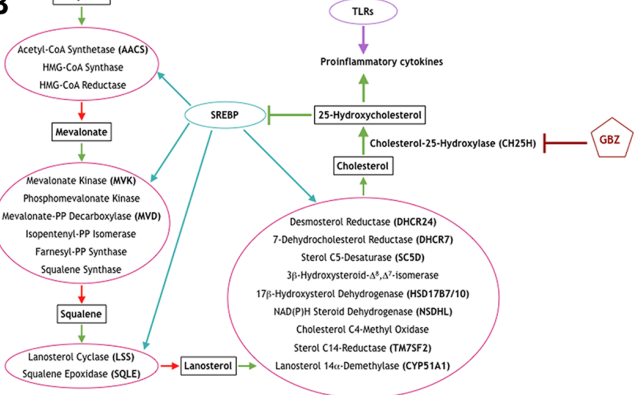

GADD34
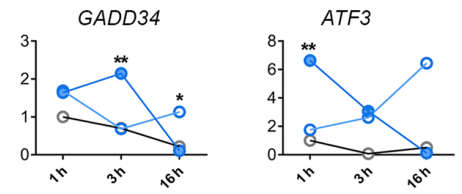

$\ominus \mathrm{NT}$

CpG + GBZ
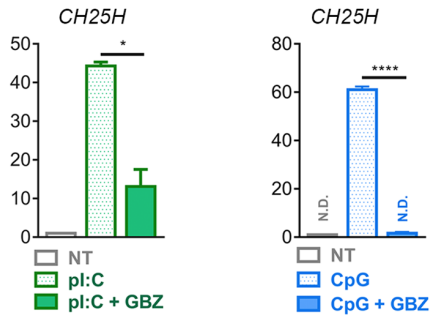

IL-6 secretion by WT DCs
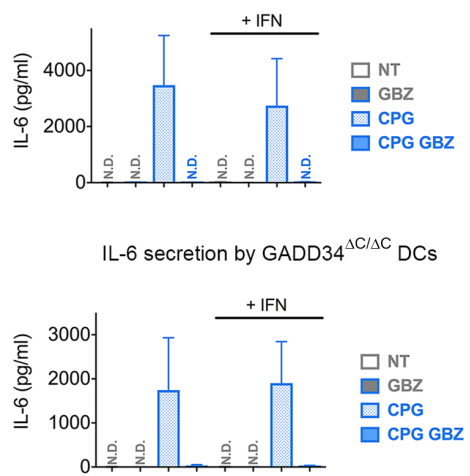

Fig. 6. GBZ reduces TLR-dependent Ch25h induction. (A) Principal components (Comp) analysis generated from microarray gene expression studies comparing GM-CSF DCs activated for 8 hours with high-molecular weight (HMW) poly $(\mathrm{l}: \mathrm{C})$ or $P$. mirabilis, with or without GBZ. (B) Graphical representation of the cholesterol biosynthesis pathway and its regulation with regard to $\mathrm{CH} 25 \mathrm{H}$, SREBP (sterol regulatory element-binding protein), GBZ, and TLRs. (C) List of genes involved in the cholesterol biosynthesis and their expression fold change (Fc) compared to untreated control cells. na, not applicable. (D) TLR9, GADD34, and ATF3 mRNA expression in mouse spleen pDCs activated with $1 \mu \mathrm{M}$ ODN 1585. CH25H mRNA level in GM-CSF DCs activated for 8h with LPS (100 ng/ml), HMW poly(l:C) (10 $\mu \mathrm{g} / \mathrm{ml})$, or $1 \mu \mathrm{M}$ ODN 1585, with or without GBZ $(50 \mu \mathrm{M})$ (bottom). (E) CH25H mRNA (left) and IL-6 secretion (right) levels in WT and GADD34 $4^{\Delta C / \triangle C}$ Flt3L-DCs treated with CpG and GBZ, exposed or not to exogenously added type I IFN. Statistical significance was assigned using two-tailed $t$ test on at least three independent experiments $\left({ }^{*} P<0.05\right.$; ${ }^{* *} P<$ $\left.0.005 ;{ }^{* * *} P<0.0005 ;{ }^{* * * *} P<0.0001\right)$.

enzyme encoded by this gene transforms cholesterol into $25-\mathrm{HC}$. $\mathrm{CH} 25 \mathrm{H}$ inactivation protects against influenza infection in mice because of decreased inflammatory-induced pathology (43). Furthermore, its enzymatic product, $25-\mathrm{HC}$, amplifies inflammation through numerous immunological effects, including suppressing IgA production (44) and B cell migration (45).

$\mathrm{CH} 25 \mathrm{H}$ activity and 25- $\mathrm{HC}$ accumulation also inhibit the sterol regulatory element-binding protein (SREBP)-dependent expression of cholesterol synthesis pathway genes (45) and affect cholesterol ho- meostasis during viral activation (46). As anticipated from $\mathrm{CH} 25 \mathrm{H}$ induction, the mRNA expression of most cholesterol synthesis genes (Fig. 6B) was decreased during DC activation but remained unchanged upon GBZ cotreatment (Fig. 6C). This inverse correlation between $C h 25 h$ transcription and SREBP-dependent gene expression suggests that GBZ prevented the feedback repression on SREBP normally mediated by $25-\mathrm{HC}$ synthesis. This conclusion was also supported by the decreased expression of MYLIP and ABC1 (Fig. 6C), whose gene products are involved in cholesterol transport and show 
increased expression upon $\mathrm{CH} 25 \mathrm{H}$-dependent cholesterol shortage induced by IFN (46). GADD34 and ATF3 expression were increased by GBZ treatment, whereas that of TLR9 remained stable, presumably due to the absence of IFN in the GBZ-treated cell culture (Fig. 6D and fig. S4A). Activating transcription factor 3 (ATF3) is therefore regulated in a stress-dependent manner by GBZ, which is an important observation because ATF3 inhibits TLR-induced cytokine production in macrophages (47), an activity that is partially mediated through direct repression of $\mathrm{Ch} 25 \mathrm{~h}$ transcription (48).

qPCR analysis of spleen pDCs revealed a strong induction of $\mathrm{CH} 25 \mathrm{H}$ in response to $\mathrm{CpG}$ stimulation, which was repressed by GBZ (Fig. 6D), thus confirming the microarray analysis of BM-DCs. We next compared the capacity of WT and GADD $34^{\Delta \mathrm{C} / \Delta \mathrm{C}}$ Flt3L-DCs to produce cytokines and express $C h 25 h$ when exposed to exogenously added type I IFN (Fig. 6E). The addition of IFN to cultured DCs did not affect the secretion of IL- 6 by CpG-activated cells and did not reverse the strong inhibition mediated by GBZ. IFN alone induced a moderate increase in Ch25h expression that was not inhibited by GBZ treatment, whereas $\mathrm{CpG}$ induction of $\mathrm{Ch} 25 \mathrm{~h}$ expression was highly sensitive to GBZ, showing the absence of a true synergetic effect between exogenous IFN addition and CpG on Ch25h mRNA expression (Fig. 6E). The lack of type I IFN production in GBZ-treated CAL-1 cells was therefore not the primary reason for the inhibition of Ch25h expression, which occurred independently of GADD34 activity (Fig. 6E).

\section{Transport of TLR9 to signaling endosomes is inhibited by GBZ and controlled by $\mathbf{2 5 - H C}$}

25-HC can induce the ISR (44), and altered cholesterol levels at the TGN (trans-Golgi network)/endosome boundaries affect recycling endosome dynamics (45). We thus hypothesized that by repressing $\mathrm{CH} 25 \mathrm{H}$ expression in CpG-stimulated DCs, GBZ could block the paracrine activity of 25-HC or altered their cholesterol metabolism, thereby changing intracellular trafficking and subsequent signaling by endocytic TLR9 (37). We therefore investigated whether the effect of GBZ on the intracellular sorting of TLR9 to endosomes was caused by a reduction of 25-HC levels and associated changes in cholesterol metabolism. We first observed that the lack of type I IFN production after GBZ treatment did not attenuate TLR9 expression in CAL-1 cells as shown by both qPCR (fig. S4A) and surface flow cytometry measurement (fig. S4B), thus ruling out a direct impact of $25-\mathrm{HC}$ on the DNA sensing ability of the cells. We used immunofluorescence proximity ligation assay (iPLA) to monitor TLR9 and MyD88 association in type I IFN signaling endosomes (49). As expected, iPLA interactions between TLR9 and the signaling adaptor MyD88 and between TLR9 and the transcription factor IRF7 were strongly increased by CpG stimulation (Fig. 7A). These close associations $(<40 \mathrm{~nm})$ were likely to occur in $\mathrm{VAMP}^{+}$sorting endosomes, because a strong association of TLR9 with VAMP3 was also observed at the time of MyD88 and IRF7 recruitment (Fig. 7A) (49). GBZ treatment impaired the recruitment of TLR9 to VAMP3 ${ }^{+}$endosomes and the interaction of TLR9 with MyD88 and IRF7, the endpoint transcription factor required for type I IFN induction by pDCs (Fig. 7A). Therefore, GBZ likely prevents the transport of TLR9 to signaling endosomes and further downstream signal transduction. We next evaluated the role of $25-\mathrm{HC}$ on TLR9 expression, trafficking, and signaling. Adding exogenous $25-\mathrm{HC}$ to CAL- 1 cells increased TLR9 expression by $25 \%$ (fig. S4B), endosomal sorting (Fig. 7B), and association with MyD88 (Fig. 7B), suggesting that 25-HC potentiated TLR9 activation in the absence of CpG stimulation. 25-HC reversed the inhibitory activity of GBZ on Myd88 and
IRF7 recruitment by TLR9 (Fig. 7B) and augmented ribosomal protein S6 phosphorylation, indicative of the reestablishment of TLR9dependent early signal transduction (Fig. 7C). In line with these observations, $25-\mathrm{HC}$ led to a modest increase in TNF- $\alpha$ mRNA expression (fig. S4C) and secretion in the presence or absence of GBZ (Fig. 7D). Together, these data suggest that in human pDCs, GBZ inhibits TLR9 signaling by interfering with its intracellular sorting to endosomal compartment, which partially depends on the synthesis of $25-\mathrm{HC}$.

\section{DISCUSSION}

Upon induction, GADD34 recruits the catalytic subunit of PP1c to dephosphorylate eIF2 $\alpha$, allowing protein synthesis to resume in a negative feedback loop that terminates UPR (unfolded protein response) signaling. We have demonstrated that GADD34 also regulates proinflammatory cytokine and type I IFN expression, both at the transcriptional and translational levels $(13,14)$. GADD34 is therefore part of the "antimicrobial stress response," which uses stress signaling cascades to potentiate innate immune responses (12). The GADD34/PP1c complex has been proposed to act directly on MAPK (mitogen-activated protein kinase) and NF- $\mathrm{BB}$ signaling by dephosphorylating TAK1 (transforming growth factor- $\beta$-activated kinase 1 ) at $\operatorname{Ser}^{412}$, which inhibits production of TNF- $\alpha$ and IL-6 upon TLR activation (50). This model has not been confirmed, but instead, deactivation of the kinase IKK by GADD34/PP1c has been proposed as an alternative means of controlling LPS-mediated activation of macrophages $(18,51)$. GADD34 expression in macrophages also enhances autophagy and suppresses apoptosis by regulating the mechanistic target of rapamycin (mTOR) signaling pathway in response to combined LPS stimulation and amino acid deprivation (52). It is, thus, likely that according to the immunostimulation and the cell types studied, major variations in the responses of GADD34-deficient cell and animals can be observed.

The $\alpha 2$-adrenergic receptor agonist GBZ, which has been used to treat hypertension, has been proposed to selectively disrupt the stressinduced dephosphorylation of eIF2 $\alpha$ by GADD34/PP1c without affecting the related constitutive repressor of eIF $2 \alpha$ phosphorylation $(\mathrm{CReP})$-phosphatase complex. We showed that the proteostasisinterfering drug GBZ efficiently inhibited endosomal TLR signaling in vitro and partially mimicked GADD34 genetic inactivation by controlling cytokine expression after endocytic TLR stimulation. However, in agreement with Crespillo-Casado and collaborators (23), we demonstrated that GBZ exerted its inhibitory activity on TLR9 independently of GADD34 function. The capacity of GBZ to block endocytic TLRs in both pDCs and B cells, two major cellular effectors of autoimmunity, suggests that this drug could also be used to treat different acute inflammatory diseases. The hypotensive activity of GBZ was not involved in its inhibition of TLR signaling, which could constitute a handicap in the clinic for many potential new indications; on the other hand, $50 \%$ of SLE patients experience hypertension generally caused by obesity, kidney disease, and long-term steroid use. Thus, the combined suppressive effect of GBZ on hypertension and TLR9 and perhaps TLR7 could benefit patients with SLE or other specific IFNdependent diseases displaying similar pathologies with recurrent flares.

Novel GBZ-like drugs that lack $\alpha 2$-adrenergic receptor agonistic activity have been designed and are currently being tested to treat neurodegenerative conditions (20). The combined ability of these drugs to interfere both with proteostasis and immunity might become a dual 
A
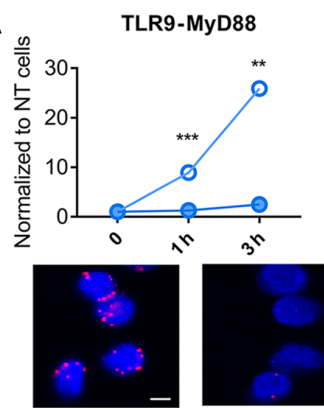

CpG

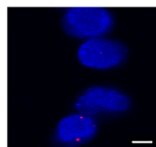

$C p G+G B Z$

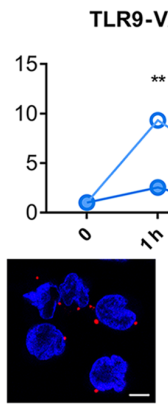

CpG
LR9-VAMP3

**

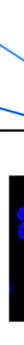

B
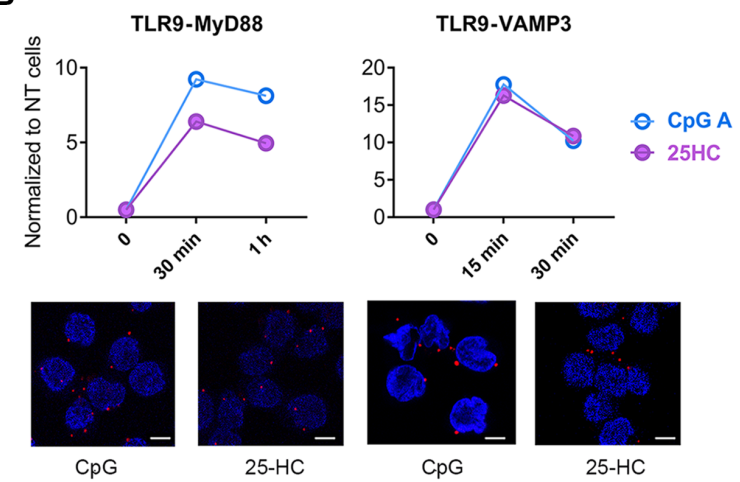

CPG 25-HC

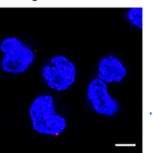

$\mathrm{CpG}+\mathrm{GBZ}$
TLR9-IRF7
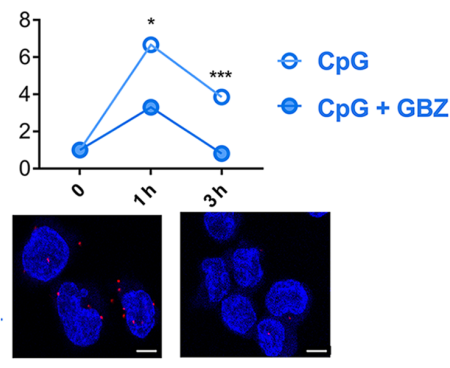

CpG

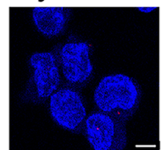

$C p G+G B Z$

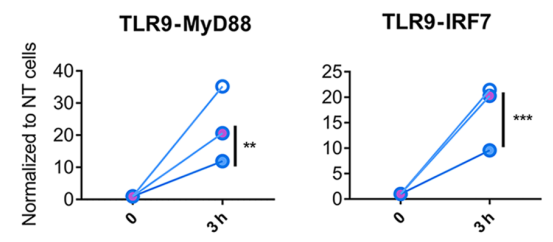

- CpG

- $\mathrm{CpG}+\mathrm{GBZ}$

- $\mathrm{CpG}+\mathrm{GBZ}+25-\mathrm{HC}$

C

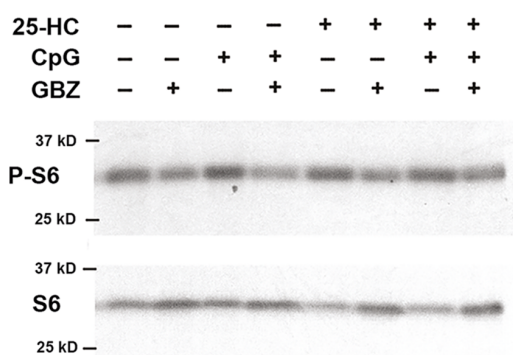

TNF- $\alpha$ protein

D

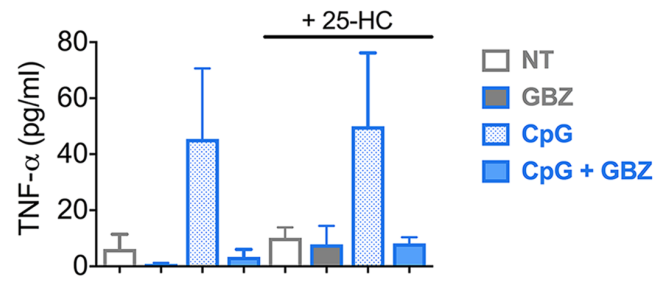

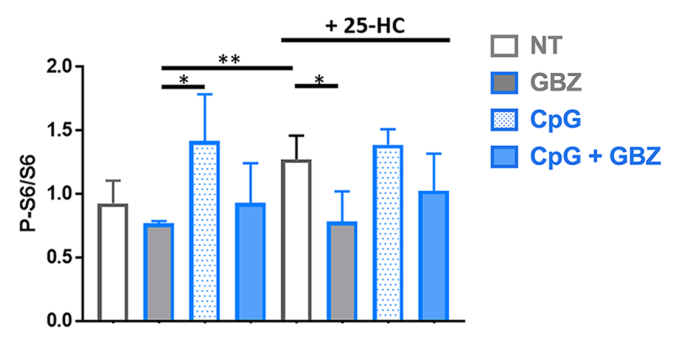

Fig. 7. 25-HC antagonizes GBZ inhibitory activity on TLR9. (A) CAL-1 cells were stimulated with $3 \mu \mathrm{M}$ ODN 2216. GBZ was added at $50 \mu \mathrm{M}$. Immunofluorescence proximity ligation assays (iPLAs) were performed at the indicated time points on the following pairs of proteins: TLR9/MyD88, TLR9/NAMP3, and TLR9/IRF7. Scale bars, $10 \mu \mathrm{M}$. (B) CAL-1 cells were stimulated with $3 \mu \mathrm{M}$ ODN 2216 with or without GBZ $(50 \mu \mathrm{M})$ and/or 25hydroxycholesterol $(25-\mathrm{HC})(100 \mathrm{nM})$. iPLAs were performed at the indicated time points on the following pairs of proteins: TLR9/MyD88, TLR9/NAMP3, TLR9/MyD88 (3 hours) or TLR9/IRF7 (3 hours). Scale bars, $10 \mu$ M. (C) Representative immunoblot for ribosomal protein $\mathrm{S} 6$ (S6) and associated TLRdependent phosphorylation in CAL-1 cells stimulated for 1 hour. Quantification of the blots is shown on the right ( $n=3$ independent experiments). (D) TNF- $\alpha$ secretion by CAL-1 cells stimulated with $3 \mu \mathrm{M}$ ODN 2216 for 3 hours with or without GBZ $(50 \mu \mathrm{M})$ and/or 25-HC (100 nM) was measured by ELISA. Statistical significance was assigned using two-tailed $t$ test on at least three independent experiments $\left({ }^{*} P<0.05 ;{ }^{*} P<0.005\right.$; ${ }^{* *} P<0.0005$ ).

advantage for the treatment of neurodegenerative diseases, which often feature increased neuronal cell death due to accumulation of misfolded proteins and acute inflammation that further triggers tissue damage and contributes to disease progression $(20,53)$. Such a dual effect could also explain the protective role of GBZ treatment in DSS (dextran sulfate sodium)-induced colitis or during sepsis induction in mice, which involves both the control of inflammatory cytokine release and the stress response in epithelial cells or hepatocytes (54-56).
We linked the inhibitory effect of GBZ on TLR9 signaling to a loss in the expression of $C h 25 h$, which encodes a cholesterol hydroxylase, and failure of TLR9 to reach signaling endosomes and recruit IRF7. In agreement with our findings, infection of Ch25h-deficient mice with influenza virus leads to decreased production of IL-6 and type I IFNs in the lungs, which enhances survival, suggesting that Ch25h is required for normal activation of signaling cascades downstream of TLR7 or TLR9. By decreasing Ch25h expression, GBZ therefore 
seems to reproduce these mechanisms and prevent TLR9 activation, which appears to be sensitive to variations in 25-HC levels.

Whether Ch25h repression is linked to proteostasis perturbation remains to be established. The transcription factor ATF3 is involved in both inflammatory and metabolic pathways $(47,57)$ and contributes to the ER stress response. ATF3 expression is augmented in response to GBZ and could therefore contribute to the suppression of $\mathrm{CH} 25 \mathrm{H} \mathrm{ex}-$ pression and associated TLR9 inhibition in nucleic acid-activated cells. This phenomenon might be particularly relevant to pDCs and B cells, which have a large ER adapted to protein secretion and depend on stress response genes for their development and survival (58).

GBZ represents a pharmacological option to interfere with inflammatory and type I IFN-dependent diseases. By reducing the restoration of protein synthesis during stress and changing the capacity of TLRs to signal in immune cells, GBZ-like compounds could be used to treat both proteotoxicity and associated inflammatory responses, which are key features of autoimmunity and neurodegeneration. Our findings that GBZ exerted its activity independently of GADD34 do not diminish the attractiveness of the GADD34/PP1c complex as a druggable target to alter cytokine production and proteostasis, but offer an alternative therapeutic target for the treatment of autoinflammatory diseases.

\section{MATERIALS AND METHODS}

\section{Reagents and molecular biology}

ODN 2006, 2216, 1585, and 1826 and HMW and LMW poly(I:C) are from InvivoGen; LPS (Escherichia coli O55:B5), clonidine, chloroquine, D-(+)-galactosamine hydrochloride, and 25-HC are from SigmaAldrich; and GBZ is from Tocris Bioscience. For qPCR, total RNAs were extracted and purified using the RNeasy Mini Kit (Qiagen). Total RNA (100 ng to $1 \mu \mathrm{g}$ ) was subjected to reverse transcription using SuperScript II. Each gene transcripts were quantified by SYBR Green method with 7500 Fast (Applied Biosystems). The relative amount of each transcript was determined by normalizing to internal housekeeping gene expression. Primer sets are indicated in table S2.

\section{Cell culture}

BM-derived DCs were differentiated in vitro from the BM of 6 to 8-weekold male mice, using either FLT3 or GM-CSF. Flt3L-DCs were used for experiments between days 6 and 7. Flt3L was produced using B16-Flt3Lexpressing cells (59). BM progenitors were plated at $1.5 \times 10^{6}$ cells $/ \mathrm{ml}, 4 \mathrm{ml}$ per well in a six-well plate, and cultivated with RPMI (GIBCO), 10\% fetal calf serum (FCS) (Sigma-Aldrich), penicillin (100 U/ml) and streptomycin $(100 \mu \mathrm{g} / \mathrm{ml})$ (GIBCO), $50 \mu \mathrm{M} \beta$-mercaptoethanol (VWR), and Flt3L. For sorted Flt3L-DCs, cells were gently harvested at day 7 with cold phosphate-buffered saline (PBS) and 2\% FCS, centrifuged at $1200 \mathrm{rpm}$ for $5 \mathrm{~min}$ at $4^{\circ} \mathrm{C}$, and then counted and stained for $30 \mathrm{~min}$ at $4^{\circ} \mathrm{C}$. Cells were sorted with a BD FACSAria SORP (BD Biosciences). The gating strategy is illustrated in Fig. 2A. The cocktail of antibodies used for sorting is listed in table S3. Cells were kept on ice all the time. After sorting, cells were suspended in supplemented Flt3L-DC medium at a concentration of $0.2 \times 10^{6}$ cells per well and plated in a 96-well plate (U bottom). GM-CSF DCs were generated in the same way using GM-CSF conditioned medium and collected for experiments at day 6 of differentiation as previously described (14).

\section{Mouse splenic cells}

Splenocytes were dissociated injecting Liberase TL, followed by 25-min incubation at $37^{\circ} \mathrm{C}$. Cells were washed using magnetic-activated cell sort- ing (MACS) buffer ( $1 \times$ PBS $+1 \%$ fetal bovine serum +2 mM EDTA) and passed in a $70-\mu \mathrm{m}$ cell strainer, and then centrifuged for $5 \mathrm{~min}$ at $4^{\circ} \mathrm{C}$. Red blood cells were lysed using the commercial buffer from eBioscience. DCs were purified using CD $11 c^{+}$selection kit from Miltenyi. Splenic DCs were then resuspended in the same medium as for Flt3L-DCs at $1 \times 10^{6}$ cells $/ \mathrm{ml}$ and plated in a 12 -well plate, $2 \mathrm{ml} \times$ well. B lymphocytes were purified using B Cell Isolation Kit, a negative selection kit from Miltenyi. B cells were then resuspended in a medium composed of RPMI (GIBCO), 10\% FCS (Sigma-Aldrich), $1 \times$ glutamine, $1 \times$ nonessential amino acids, $10 \mathrm{mM}$ Hepes (all from GIBCO), and $50 \mu \mathrm{M} \beta$-mercaptoethanol (VWR). Cells were plated at $1 \times 10^{6}$ cells per well in a flat 96-well plate.

\section{Human pDCs and B cells}

Human peripheral blood mononuclear cells were isolated from whole blood from volunteer donors by density gradient using Ficoll-Paque PLUS (GE Healthcare), followed by a density gradient of Percoll PLUS (GE Healthcare), to separate the lymphocytic fraction containing B cells from the monocytic lineage fraction containing pDCs. Both cell types were isolated using a negative selection kit from Miltenyi: B Cell Isolation Kit II (human; for B cells) and Plasmacytoid Dendritic Cell Isolation Kit II (human; for pDCs). pDCs were cultured at $0.5 \times 10^{6}$ cells $/ \mathrm{ml}$ in RPMI 1640 medium containing 10\% FCS and complemented with IL-3 (10 ng/ml). B lymphocytes were cultured at $0.5 \times 10^{6}$ cells $/ \mathrm{ml}$ in RPMI 1640 medium containing 10\% FCS and complemented with penicillin $(100 \mathrm{U} / \mathrm{ml})$, streptomycin $(100 \mu \mathrm{g} / \mathrm{ml}$; GIBCO), and $1 \times$ L-glutamine (GIBCO). Both cell types were plated in a 96-well plate (U bottom).

\section{Cell lines}

HEK-Blue TLR cells (Invivogen) were grown in Dulbecco's modified Eagle's medium, with $10 \%$ of FCS (Sigma-Aldrich) and a proper selection of antibiotics. A20 cells were grown in RPMI (GIBCO), 10\% FCS (Sigma-Aldrich), and $50 \mu \mathrm{M} \beta$-mercaptoethanol (VWR). CAL-1 cells were grown in RPMI (GIBCO), 10\% FCS (Sigma-Aldrich), $2 \mathrm{mM}$ L-glutamine, $1 \times$ nonessential amino acids, $10 \mathrm{mM}$ Hepes, and $1 \mathrm{mM}$ sodium pyruvate (all from GIBCO). Cells were plated 16 hours before the start of experiments in a 12 -well plate at $1 \times 10^{6}$ cells $/ \mathrm{ml}, 1 \mathrm{ml} \times$ well, in a complete medium with $1 \%$ FCS. All cell lines were mycoplasmafree and kept at $37^{\circ} \mathrm{C}$ and $5 \% \mathrm{CO}_{2}$.

\section{Flow cytometry}

Cell suspensions were incubated with the antibody cocktail diluted in cold fluorescence-activated cell sorting (FACS) buffer (PBS, 2\% FCS, and $2 \mathrm{mM} \mathrm{EDTA)} \mathrm{for} 30 \mathrm{~min}$ at $4^{\circ} \mathrm{C}$. For intracellular staining, cells were permeabilized with FIX \& PERM Kit (BD Biosciences). Flow cytometry was conducted using the LSR 561 machine (BD Biosciences), and data were analyzed with FlowJo (Tree Star). The antibodies used are listed in tables S3 and S4.

\section{Confocal microscopy and PLA}

CAL- 1 cells were harvested, centrifuged for $5 \mathrm{~min}$ at $4^{\circ} \mathrm{C}$, then resuspended in prewarmed serum-free medium and dropped on a $12-\mathrm{mm}$ coverslip, and covered with $1 \%$ alcian blue. The coverslips were then incubated for $20 \mathrm{~min}$ at $37^{\circ} \mathrm{C}$ and fixed with $3 \%$ paraformaldehyde. iPLAs were performed using the Duolink Kit (Sigma-Aldrich) according to the manufacturer's instruction. The following primary antibodies are used: anti-TLR9 (H-100), Santa Cruz Biotechnology, rabbit polyclonal (1:50); anti-Vamp3 (N-12), Santa Cruz Biotechnology, 
goat polyclonal (1:100); anti-human MyD88, R\&D Systems, goat polyclonal (1:100); and anti-human IRF7 (G-8), Santa Cruz Biotechnology, mouse IgG2a (1:100). Duolink PLA Probe anti-rabbit PLUS and antigoat or anti-mouse MINUS, conjugated with oligonucleotides, were used as secondary antibodies. The samples were incubated in the ligation solution consisting of Duolink Ligation Stock (1:5) and Duolink Ligase (1:40). Detection of the amplified probe was done with the Duolink Detection Kit Orange. The images were taken with the confocal microscope LSM 580 (63× objective; Carl Zeiss) and accompanying imaging software.

\section{Gene expression analysis}

Total RNA was isolated with the RNeasy kit (Qiagen). Complementary DNA was synthesized with random hexamers and SuperScript II reverse transcriptase (Invitrogen). Real-time qPCR analysis was performed with Applied Biosystems PRISM 7700 Sequence Detection System. The list of the primers used is reported in table S4. For Affymetrix microarray analysis, GM-CSF DCs were cultured in RPMI supplemented with $5 \%$ FCS, $50 \mu \mathrm{M} \beta$-mercaptoethanol, and GM-CSF. Cells differentiated for 6 days were treated for 8 hours with microbial stimuli and harvested before lysis. Control and P. mirabilis-treated DCs were incubated with the bacteriostatic chloramphenicol to avoid bacterial growth. GBZ was used at $50 \mu \mathrm{M}$. Hybridization to arrays (Affymetrix GeneChip Mouse Gene 1.0 ST) and image scanning were performed according to the Affymetrix Expression Analysis Technical Manual. Gene expression microarray raw data were normalized using limmaGUI software (R/ Bioconductor). Data can be accessed through the Gene Expression Omnibus (GEO) repository under accession number GSE90831.

\section{Translation intensity measurement}

Puromycin labeling for measuring the intensity of translation was performed as previously described (41). Puromycin (P8833; min $98 \%$ thin-layer chromatography, cell culture-tested, and diluted in PBS; Sigma-Aldrich) was added at $2.5 \mu \mathrm{g} / \mathrm{ml}$ in the culture medium, and the cells were incubated for $15 \mathrm{~min}$ at $37^{\circ} \mathrm{C}$ and $5 \% \mathrm{CO}_{2}$. Cells were fixed and permeabilized with Cytofix/Cytoperm buffer (BD Biosciences), stained with the anti-puromycin antibody (12D10) directly coupled with Alexa Fluor 488, and diluted in Perm/Wash buffer (BD Biosciences). Flow cytometry was conducted using the LSR 561 machine (BD Biosciences), and data were analyzed with FlowJo (Tree Star).

\section{Immunoblotting}

Cells were lysed in 1\% Triton X-100, $50 \mathrm{mM}$ Hepes, $10 \mathrm{mM} \mathrm{NaCl}$, $2.5 \mathrm{mM} \mathrm{MgCl}_{2}, 2 \mathrm{mM}$ EDTA, and 10\% glycerol and supplemented with cOmplete Mini Protease Inhibitor Cocktail Tablets (Roche). Protein quantification was performed using the BCA (bicinchoninic acid) Protein Assay (Pierce). Twenty to $25 \mu \mathrm{g}$ of Triton X-100 soluble material was loaded on $10 \%$ SDS-polyacrylamide gel electrophoresis before immunoblotting and chemiluminescence detection (SuperSignal West Pico Chemiluminescent Substrate, Pierce). The rabbit polyclonal antibody against eIF2 $\alpha$ (D7D3) was purchased from Cell Signaling Technology. The rabbit polyclonal antibody against phosphorylated eIF $2 \alpha$ $\left(\mathrm{Ser}^{51}\right)$ was from Abcam. Mouse monoclonal antibodies against $\beta$-actin were from Sigma-Aldrich and Upstate Biotechnology. Secondary antibodies were purchased from Jackson ImmunoResearch Laboratories.

\section{Cytokine measurement}

Mouse IFN- $\beta$ quantification in culture supernatant was performed using the Mouse Interferon Beta ELISA kit (PBL InterferonSource).
Mouse IL-6, TNF- $\alpha$, IL-10, human TNF- $\alpha$, and human IFN- $\alpha$ were quantified using an appropriate ELISA kit (eBioscience) according to the manufacturer's instructions.

\section{Animal studies}

WT C57BL/6 mice were purchased from The Jackson Laboratory. GADD $34^{\Delta \mathrm{C} / \Delta \mathrm{C}}$ mice (FVB background) and WT littermate were originally obtained from L. Wrabetz (DIBIT, San Raffaele Scientific Institute, Milan) and maintained in the animal facility of Centre d'Immunologie de Marseille-Luminy (CIML) under specific pathogen-free conditions. This study was carried out in strict accordance with the recommendations in the Guide for the Care and Use of Laboratory Animals of the French Ministry of Agriculture and of the European Union. Animals were housed in CIML animal facilities accredited by the French Ministry of Agriculture to perform experiments on live mice. All animal experiments were approved by Direction Départementale des Services Vétérinaires des Bouches du Rhône (approval number A13-543). All efforts were made to minimize animal suffering.

\section{TMPD model}

WT female 6-week-old C57BL/6 mice were injected intraperitoneally with $500 \mu \mathrm{l}$ of TMPD (Sigma-Aldrich) or PBS. From days 1 to 13, mice were injected intraperitoneally every 2 days with GBZ or PBS/dimethyl sulfoxide (DMSO) $(2 \mathrm{mg} / \mathrm{kg}$ ). Mice were injected intraperitoneally on day 7 with ODN 1585 (50 $\mu \mathrm{g} / 20 \mathrm{~g}$ of mouse) or PBS. Mice were sacrificed at day 14 or after 6 months. At day 14, PECs were taken for flow cytometry analysis. After 6 months, kidneys were taken for immunohistochemistry. During the 6 months between injection and sacrifice, blood serum collection was performed once a month, from 2 months after the injection of TMPD up to 1 week before the animal sacrifice. Serum was used to evaluate the concentration of circulating autoantibodies. Monitoring of anti-RNA autoantibody titer was performed by coating ELISA plates with $50 \mu \mathrm{l}$ per well of mouse RNA or DNA $(5 \mu \mathrm{g} / \mathrm{ml})$ in PBS, which were incubated overnight at $4^{\circ} \mathrm{C}$. The next day, plates were incubated with 1:50 or 1:100 diluted serum samples in working solution (PBS $+0.05 \%$ Tween $20+1 \%$ bovine serum albumin), and the assay was developed with horseradish peroxidase-labeled goat anti-mouse IgG (SouthernBiotech) (60).

\section{Cytokine shock model}

WT female 8-week-old C57BL/6 mice were injected intraperitoneally with GBZ, clonidine, or PBS/DMSO (2 mg/kg). One hour later, they were injected intraperitoneally with $20 \mathrm{mg}$ per mouse of $\mathrm{D}-\mathrm{GalN}$ and ODN 1826 (50 $\mu \mathrm{g} / 20 \mathrm{~g}$ ) (or PBS). Mice survival was checked every 12 hours for up to 48 hours. For some experiments, blood sera were collected 1 and 3 hours after the injection of D-GalN. The serum was used to measure circulating cytokines (TNF- $\alpha$, IL-6, IFN- $\beta$, IL-10, and IL-12). For some experiments, the liver was collected for immunohistochemistry after 2 days. For intraperitoneal injections, 1-ml syringes and 25-gauge needles were used. Blood was collected from the cheek with an 18-gauge needle; for the TMPD model, no more than $200 \mu \mathrm{l}$ was collected each time in accordance with ethical requirements.

\section{Tissue histology}

Mouse kidneys and livers were fixed in $10 \%$ buffered formalin for 24 hours, dehydrated, and embedded in paraffin. Tissue sections $(3.5 \mu \mathrm{m})$ were cut using the Leica microtome RM2245. Hematoxylin and eosin staining was performed automatically with a Leica AutoStainer XL. Finally, the slides were mounted with "entellan" and kept at room temperature. 
Biopsies were analyzed by an anatomopathologist, who assigned the clinical score while blinded to the treatments. Pictures were taken with a Nikon Eclipse.

\section{Anatomopathology scoring system for liver damage}

Lobular inflammation was assessed as follows: 0 , no inflammation; 1 , mild lobular inflammation ( $<10 \%$ of liver parenchyma); 2 , moderate lobular inflammation (10 to $50 \%$ of liver parenchyma); and 3 , severe lobular inflammation ( $>50 \%$ of liver parenchyma). Portal inflammation was assessed as follows: 0 , no portal inflammation; 1 , mild portal inflammation (less than one-third of portal tracts); 2, moderate portal inflammation (about $50 \%$ of portal tracts); and 3, severe portal inflammation (greater than two-thirds of portal tracts). The inflammation score was obtained by adding the portal and lobular inflammation scores. Necrosis was assessed as follows: 0 , no necrosis; $1,<10 \%$ necrosis of liver parenchyma; 2, 10 to $25 \%$ necrosis of liver parenchyma; and 3, $>25 \%$ necrosis of liver parenchyma. The total histological score was obtained by adding the inflammation and necrosis scores.

\section{Statistical analysis}

Statistical analysis was performed with GraphPad Prism software. When several conditions were compared, we performed a one-way analysis of variance (ANOVA), followed by a Tukey range test to assess the significance among pairs of conditions. When only two conditions were tested, we performed Student's $t$ test or Welch's $t$ test (according to the validity of the homoscedasticity hypothesis). Statistical analysis on survival curves was performed using log-rank test, followed by the Benjamini-Yekutieli correction when required.

\section{SUPPLEMENTARY MATERIALS}

www.sciencesignaling.org/cgi/content/full/11/514/eaam8104/DC1

Fig. S1. GBZ inhibits TLR9 signaling in B cells.

Fig. S2. TMPD and CpG synergize to promote inflammation.

Fig. S3. GBZ does not inhibit endosomal acidification or protein synthesis.

Fig. S4. GBZ and 25-HC do not reduce TLR9 abundance in pDCs.

Table S1. List of genes in DCs with increased expression in response to poly $(1: C)$ or $P$. mirabilis that is inhibited by GBZ.

Table S2. List of the primers used for gene expression analysis by qPCR.

Table S3. List of the antibodies used for sorting DC1, DC2, and pDCs from Flt3L-DC culture. Table S4. List of the antibodies used for flow cytometry.

\section{REFERENCES AND NOTES}

1. S. Akira, S. Uematsu, O. Takeuchi, Pathogen recognition and innate immunity. Cell 124, 783-801 (2006).

2. T. Kawai, S. Akira, The role of pattern-recognition receptors in innate immunity: Update on Toll-like receptors. Nat. Immunol. 11, 373-384 (2010).

3. S. E. Ewald, A. Engel, J. Lee, M. Wang, M. Bogyo, G. M. Barton, Nucleic acid recognition by Toll-like receptors is coupled to stepwise processing by cathepsins and asparagine endopeptidase. J. Exp. Med. 208, 643-651 (2011).

4. F. E. Sepulveda, S. Maschalidi, R. Colisson, L. Heslop, C. Ghirelli, E. Sakka, A.-M. Lennon-Duménil, S. Amigorena, L. Cabanie, B. Manoury, Critical role for asparagine endopeptidase in endocytic Toll-like receptor signaling in dendritic cells. Immunity 31, 737-748 (2009).

5. S. Bauer, C. J. Kirschning, H. Häcker, V. Redecke, S. Hausmann, S. Akira, H. Wagner, G. B. Lipford, Human TLR9 confers responsiveness to bacterial DNA via species-specific CpG motif recognition. Proc. Natl. Acad. Sci. U.S.A. 98, 9237-9242 (2001).

6. H. Hemmi, O. Takeuchi, T. Kawai, T. Kaisho, S. Sato, H. Sanjo, M. Matsumoto, K. Hoshino, H. Wagner, K. Takeda, S. Akira, A Toll-like receptor recognizes bacterial DNA. Nature $\mathbf{4 0 8}$ 740-745 (2000).

7. M. Gilliet, W. Cao, Y.-J. Liu, Plasmacytoid dendritic cells: Sensing nucleic acids in viral infection and autoimmune diseases. Nat. Rev. Immunol. 8, 594-606 (2008).

8. K. Honda, Y. Ohba, H. Yanai, H. Negishi, T. Mizutani, A. Takaoka, C. Taya, T. Taniguchi, Spatiotemporal regulation of MyD88-IRF-7 signalling for robust type-I interferon induction. Nature 434, 1035-1040 (2005).
9. R. Lande, D. Ganguly, V. Facchinetti, L. Frasca, C. Conrad, J. Gregorio, S. Meller, G. Chamilos, R. Sebasigari, V. Riccieri, R. Bassett, H. Amuro, S. Fukuhara, T. Ito, Y.-J. Liu, M. Gilliet, Neutrophils activate plasmacytoid dendritic cells by releasing self-DNApeptide complexes in systemic lupus erythematosus. Sci. Transl. Med. 3, 73 ra19 (2011).

10. J.-E. Gottenberg, N. Cagnard, C. Lucchesi, F. Letourneur, S. Mistou, T. Lazure, S. Jacques, N. Ba, M. Ittah, C. Lepajolec, M. Labetoulle, M. Ardizzone, J. Sibilia, C. Fournier, G. Chiocchia, X. Mariette, Activation of IFN pathways and plasmacytoid dendritic cell recruitment in target organs of primary Sjögren's syndrome. Proc. Natl. Acad. Sci. U.S.A. 103, 2770-2775 (2006).

11. D. Ron, P. Walter, Signal integration in the endoplasmic reticulum unfolded protein response. Nat. Rev. Mol. Cell Biol. 8, 519-529 (2007).

12. N. Cláudio, A. Dalet, E. Gatti, P. Pierre, Mapping the crossroads of immune activation and cellular stress response pathways. EMBO J. 32, 1214-1224 (2013).

13. G. Clavarino, N. Cláudio, T. Couderc, A. Dalet, D. Judith, V. Camosseto, E. K. Schmidt, T. Wenger, M. Lecuit, E. Gatti, P. Pierre, Induction of GADD34 is necessary for dsRNA-dependent interferon- $\beta$ production and participates in the control of Chikungunya virus infection. PLOS Pathog. 8, e1002708 (2012).

14. G. Clavarino, N. Cláudio, A. Dalet, S. Terawaki, T. Couderc, L. Chasson, M. Ceppi, E. K. Schmidt, T. Wenger, M. Lecuit, E. Gatti, P. Pierre, Protein phosphatase 1 subunit Ppp1r15a/GADD34 regulates cytokine production in polyinosinic:polycytidylic acidstimulated dendritic cells. Proc. Natl. Acad. Sci. U.S.A. 109, 3006-3011 (2012).

15. P. Walter, D. Ron, The unfolded protein response: From stress pathway to homeostatic regulation. Science 334, 1081-1086 (2011).

16. I. Novoa, H. Zeng, H. P. Harding, D. Ron, Feedback inhibition of the unfolded protein response by GADD34-mediated dephosphorylation of elF2 $\alpha$. J. Cell Biol. 153, 1011-1022 (2001).

17. I. Novoa, Y. Zhang, H. Zeng, R. Jungreis, H. P. Harding, D. Ron, Stress-induced gene expression requires programmed recovery from translational repression. $E M B O$ J. 22, 1180-1187 (2003).

18. S. Ito, Y. Tanaka, R. Oshino, S. Okado, M. Hori, K.-i. Isobe, GADD34 suppresses lipopolysaccharide-induced sepsis and tissue injury through the regulation of macrophage activation. Cell Death Dis. 7, e2219 (2016).

19. P. Tsaytler, H. P. Harding, D. Ron, A. Bertolotti, Selective inhibition of a regulatory subunit of protein phosphatase 1 restores proteostasis. Science 332, 91-94 (2011).

20. I. Das, A. Krzyzosiak, K. Schneider, L. Wrabetz, M. D'Antonio, N. Barry, A. Sigurdardottir, A. Bertolotti, Preventing proteostasis diseases by selective inhibition of a phosphatase regulatory subunit. Science 348, 239-242 (2015).

21. B. Holmes, R. N. Brogden, R. C. Heel, T. M. Speight, G. S. Avery, Guanabenz: A review of its pharmacodynamic properties and therapeutic efficacy in hypertension. Drugs $\mathbf{2 6}$ 212-229 (1983).

22. S. W. Way, J. R. Podojil, B. L. Clayton, A. Zaremba, T. L. Collins, R. B. Kunjamma, A. P. Robinson, P. Brugarolas, R. H. Miller, S. D. Miller, B. Popko, Pharmaceutical integrated stress response enhancement protects oligodendrocytes and provides a potential multiple sclerosis therapeutic. Nat. Commun. 6, 6532 (2015).

23. A. Crespillo-Casado, J. E. Chambers, P. M. Fischer, S. J. Marciniak, D. Ron, PPP1R15Amediated dephosphorylation of elF $2 \alpha$ is unaffected by Sephin 1 or Guanabenz. eLife 6 , e26109 (2017).

24. H. P. Harding, Y. Zhang, D. Scheuner, J.-J. Chen, R. J. Kaufman, D. Ron, Ppp1r15 gene knockout reveals an essential role for translation initiation factor 2 alpha (elF2 $\alpha$ ) dephosphorylation in mammalian development. Proc. Natl. Acad. Sci. U.S.A. 106, 1832-1837 (2009).

25. W. H. Reeves, P. Y. Lee, J. S. Weinstein, M. Satoh, L. Lu, Induction of autoimmunity by pristane and other naturally occurring hydrocarbons. Trends Immunol. 30, 455-464 (2009).

26. S. H. Naik, A. I. Proietto, N. S. Wilson, A. Dakic, P. Schnorrer, M. Fuchsberger, M. H. Lahoud, M. O'Keeffe, Q.-x. Shao, W.-f. Chen, J. A. Villadangos, K. Shortman, L. Wu, Cutting edge: Generation of splenic $\mathrm{CD}^{+}$and $\mathrm{CD} 8^{-}$dendritic cell equivalents in Fms-like tyrosine kinase 3 ligand bone marrow cultures. J. Immunol. 174, 6592-6597 (2005).

27. M. Guilliams, C.-A. Dutertre, C. L. Scott, N. McGovern, D. Sichien, S. Chakarov, S. Van Gassen, J. Chen, M. Poidinger, S. De Prijck, S. J. Tavernier, I. Low, S. E. Irac, C. N. Mattar, H. R. Sumatoh, G. H. Low, T. J. Chung, D. K. Chan, K. K. Tan, T. L. Hon, E. Fossum, B. Bogen, M. Choolani, J. K. Chan, A. Larbi, H. Luche, S. Henri, Y. Saeys, E. W. Newell, B. N. Lambrecht, B. Malissen, F. Ginhoux, Unsupervised high-dimensional analysis aligns dendritic cells across tissues and species. Immunity 45, 669-684 (2016).

28. T. Maeda, K. Murata, T. Fukushima, K. Sugahara, K. Tsuruda, M. Anami, Y. Onimaru, K. Tsukasaki, M. Tomonaga, R. Moriuchi, H. Hasegawa, Y. Yamada, S. Kamihira, A novel plasmacytoid dendritic cell line, CAL-1, established from a patient with blastic natural killer cell lymphoma. Int. J. Hematol. 81, 148-154 (2005).

29. C. Guiducci, C. Ghirelli, M.-A. Marloie-Provost, T. Matray, R. L. Coffman, Y.-J. Liu, F. J. Barrat, V. Soumelis, PI3K is critical for the nuclear translocation of IRF-7 and type I IFN production by human plasmacytoid predendritic cells in response to TLR activation. J. Exp. Med. 205, 315-322 (2008) 
30. H. Lelouard, E. K. Schmidt, V. Camosseto, G. Clavarino, M. Ceppi, H.-T. Hsu, P. Pierre, Regulation of translation is required for dendritic cell function and survival during activation. J. Cell Biol. 179, 1427-1439 (2007).

31. F. G. Vieira, Q. Ping, A. J. Moreno, J. D. Kidd, K. Thompson, B. Jiang, J. M. Lincecum, M. Z. Wang, G. S. De Zutter, V. R. Tassinari, B. Levine, T. Hatzipetros, A. Gill, S. Perrin, Guanabenz treatment accelerates disease in a mutant SOD1 mouse model of ALS. PLOS ONE 10, e0135570 (2015).

32. H.-Q. Jiang, M. Ren, H.-Z. Jiang, J. Wang, J. Zhang, X. Yin, S.-Y. Wang, Y. Qi, X.-D. Wang, H.-L. Feng, Guanabenz delays the onset of disease symptoms, extends lifespan, improves motor performance and attenuates motor neuron loss in the SOD1 G93A mouse model of amyotrophic lateral sclerosis. Neuroscience 277, 132-138 (2014).

33. R. R. Ruffolo Jr., A. J. Nichols, J. M. Stadel, J. P. Hieble, Structure and function of alphaadrenoceptors. Pharmacol. Rev. 43, 475-505 (1991).

34. A. Mignon, N. Rouquet, M. Fabre, S. Martin, J. C. Pages, J. F. Dhainaut, A. Kahn, P. Briand, V. Joulin, LPS challenge in D-galactosamine-sensitized mice accounts for caspase-dependent fulminant hepatitis, not for septic shock. Am. J. Respir. Crit. Care Med. 159, 1308-1315 (1999).

35. D. C. Nacionales, J. S. Weinstein, X.-J. Yan, E. Albesiano, P. Y. Lee, K. M. Kelly-Scumpia, R. Lyons, M. Satoh, N. Chiorazzi, W. H. Reeves, B cell proliferation, somatic hypermutation, class switch recombination, and autoantibody production in ectopic lymphoid tissue in murine lupus. J. Immunol. 182, 4226-4236 (2009).

36. P. Y. Lee, Y. Kumagai, Y. Li, O. Takeuchi, H. Yoshida, J. Weinstein, E. S. Kellner, D. Nacionales, T. Barker, K. Kelly-Scumpia, N. van Rooijen, H. Kumar, T. Kawai, M. Satoh, S. Akira, W. H. Reeves, TLR7-dependent and FcyR-independent production of type I interferon in experimental mouse lupus. J. Exp. Med. 205, 2995-3006 (2008).

37. L. Bossaller, A. Christ, K. Pelka, K. Nundel, P.-I. Chiang, C. Pang, N. Mishra, P. Busto, R. G. Bonegio, R. E. Schmidt, E. Latz, A. Marshak-Rothstein, TLR9 deficiency leads to accelerated renal disease and myeloid lineage abnormalities in pristane-induced murine lupus. J. Immunol. 197, 1044-1053 (2016).

38. H. Zhuang, C. Szeto, S. Han, L. Yang, W. H. Reeves, Animal models of interferon signature positive lupus. Front. Immunol. 6, 291 (2015).

39. A. Savina, P. Vargas, P. Guermonprez, A.-M. Lennon, S. Amigorena, Measuring pH, ROS production, maturation, and degradation in dendritic cell phagosomes using cytofluorometry-based assays. Methods Mol. Biol. 595, 383-402 (2010).

40. P. Pierre, I. Shachar, D. Matza, E. Gatti, R. A. Flavell, I. Mellman, Invariant chain controls H2-M proteolysis in mouse splenocytes and dendritic cells. J. Exp. Med. 191, 1057-1062 (2000).

41. E. K. Schmidt, G. Clavarino, M. Ceppi, P. Pierre, SUnSET, a nonradioactive method to monitor protein synthesis. Nat. Methods 6, 275-277 (2009).

42. A. R. Tall, L. Yvan-Charvet, Cholesterol, inflammation and innate immunity. Nat. Rev. Immunol. 15, 104-116 (2015).

43. E. S. Gold, A. H. Diercks, I. Podolsky, R. L. Podyminogin, P. S. Askovich, P. M. Treuting, A. Aderem, 25-Hydroxycholesterol acts as an amplifier of inflammatory signaling. Proc. Natl. Acad. Sci. U.S.A. 111, 10666-10671 (2014).

44. S. Hannedouche, J. Zhang, T. Yi, W. Shen, D. Nguyen, J. P. Pereira, D. Guerini, B. U. Baumgarten, S. Roggo, B. Wen, R. Knochenmuss, S. Noël, F. Gessier, L. M. Kelly, M. Vanek, S. Laurent, I. Preuss, C. Miault, I. Christen, R. Karuna, W. Li, D.-I. Koo, T. Suply, C. Schmedt, E. C. Peters, R. Falchetto, A. Katopodis, C. Spanka, M.-O. Roy, M. Detheux, Y. A. Chen, P. G. Schultz, C. Y. Cho, K. Seuwen, J. G. Cyster, A. W. Sailer, Oxysterols direct immune cell migration via EBI2. Nature 475, 524-527 (2011).

45. J. G. Cyster, E. V. Dang, A. Reboldi, T. Yi, 25-Hydroxycholesterols in innate and adaptive immunity. Nat. Rev. Immunol. 14, 731-743 (2014).

46. M. Blanc, W. Y. Hsieh, K. A. Robertson, K. A. Kropp, T. Forster, G. Shui, P. Lacaze, S. Watterson, S. J. Griffiths, N. J. Spann, A. Meljon, S. Talbot, K. Krishnan, D. F. Covey, M. R. Wenk, M. Craigon, Z. Ruzsics, J. Haas, A. Angulo, W. J. Griffiths, C. K. Glass, Y. Wang, P. Ghazal, The transcription factor STAT-1 couples macrophage synthesis of 25hydroxycholesterol to the interferon antiviral response. Immunity 38, 106-118 (2013).

47. M. Gilchrist, V. Thorsson, B. Li, A. G. Rust, M. Korb, J. C. Roach, K. Kennedy, T. Hai, H. Bolouri, A. Aderem, Systems biology approaches identify ATF3 as a negative regulator of Toll-like receptor 4. Nature 441, 173-178 (2006).

48. E. S. Gold, S. A. Ramsey, M. J. Sartain, J. Selinummi, I. Podolsky, D. J. Rodriguez, R. L. Moritz, A. Aderem, ATF3 protects against atherosclerosis by suppressing 25-hydroxycholesterolinduced lipid body formation. J. Exp. Med. 209, 807-817 (2012).

49. A. Combes, V. Camosseto, P. N'Guessan, R. J. Argüello, J. Mussard, C. Caux, N. Bendriss-Vermare, P. Pierre, E. Gatti, BAD-LAMP controls TLR9 trafficking and signalling in human plasmacytoid dendritic cells. Nat. Commun. 8, 913 (2017).
50. M. Gu, C. Ouyang, W. Lin, T. Zhang, X. Cao, Z. Xia, X. Wang, Phosphatase holoenzyme PP1/GADD34 negatively regulates TLR response by inhibiting TAK1 serine 412 phosphorylation. J. Immunol. 192, 2846-2856 (2014).

51. H.-Y. Li, H. Liu, C.-H. Wang, J.-Y. Zhang, J.-H. Man, Y.-F. Gao, P.-J. Zhang, W.-H. Li, J. Zhao, X. Pan, T. Zhou, W.-L. Gong, A.-L. Li, X.-M. Zhang, Deactivation of the kinase IKK by CUEDC2 through recruitment of the phosphatase PP1. Nat. Immunol. 9, 533-541 (2008).

52. S. Ito, Y. Tanaka, R. Oshino, K. Aiba, S. Thanasegaran, N. Nishio, K.-I. Isobe, GADD34 inhibits activation-induced apoptosis of macrophages through enhancement of autophagy. Sci. Rep. 5, 8327 (2015).

53. R. M. Ransohoff, How neuroinflammation contributes to neurodegeneration. Science $\mathbf{3 5 3}$, 777-783 (2016).

54. X. Tréton, E. Pedruzzi, C. Guichard, Y. Ladeiro, S. Sedghi, M. Vallée, N. Fernandez, E. Bruyère, P.-L. Woerther, R. Ducroc, N. Montcuquet, J.-N. Freund, I. Van Seuningen, F. Barreau, A. Marah, J.-P. Hugot, D. Cazals-Hatem, Y. Bouhnik, F. Daniel, E. Ogier-Denis, Combined NADPH oxidase 1 and interleukin 10 deficiency induces chronic endoplasmic reticulum stress and causes ulcerative colitis-like disease in mice. PLOS ONE 9, e101669 (2014).

55. Y. Tanaka, S. Ito, R. Oshino, N. Chen, N. Nishio, K.-i. Isobe, Effects of growth arrest and DNA damage-inducible protein 34 (GADD34) on inflammation-induced colon cancer in mice. Br. J. Cancer 113, 669-679 (2015).

56. J. Perego, C. Bourbon, L. Chasson, C. Laprie, L. Spinelli, V. Camosseto, E. Gatti, P. Pierre, Guanabenz prevents D-galactosamine/lipopolysaccharide-induced liver damage and mortality. Front. Immunol. 8, 679 (2017).

57. E. J. Zmuda, L. Qi, M. X. Zhu, R. G. Mirmira, M. R. Montminy, T. Hai, The roles of ATF3, an adaptive-response gene, in high-fat-diet-induced diabetes and pancreatic $\beta$-cell dysfunction. Mol. Endocrinol. 24, 1423-1433 (2010).

58. Y. Ma, Y. Shimizu, M. J. Mann, Y. Jin, L. M. Hendershot, Plasma cell differentiation initiates a limited ER stress response by specifically suppressing the PERK-dependent branch of the unfolded protein response. Cell Stress Chaperones 15, 281-293 (2010).

59. G. Dranoff, E. Jaffee, A. Lazenby, P. Golumbek, H. Levitsky, K. Brose, V. Jackson, H. Hamada, D. Pardoll, R. C. Mulligan, Vaccination with irradiated tumor cells engineered to secrete murine granulocyte-macrophage colony-stimulating factor stimulates potent, specific, and long-lasting anti-tumor immunity. Proc. Natl. Acad. Sci. U.S.A. 90, 3539-3543 (1993).

60. O. Demaria, P. P. Pagni, S. Traub, A. de Gassart, N. Branzk, A. J. Murphy, D. M. Valenzuela, G. D. Yancopoulos, R. A. Flavell, L. Alexopoulou, TLR8 deficiency leads to autoimmunity in mice. J. Clin. Invest. 120, 3651-3662 (2010).

Acknowledgments: We thank all CIML core facilities for expert assistance and T. Lawrence for manuscript editing. Funding: This work was supported by grants from the SANOFI Innate Immunocytes in Health and Disease (I2HD) initiative, Fondation de la Recherche Médicale (FRM) (\#DEQ20140329536 to P.P.), and Agence Nationale de la Recherche (\#ANR-12-BSV2-0025-01, \#ANR-FCT 12-ISV3-0002-01, \#ANR-11-LABEX-0054, \#ANR-11-LABEX-0043, \#ANR-10-IDEX-0001-02 PSL*, and \#ANR-11-IDEX-0001-02). P.P. and E.G. are supported by the llídio Pinho Foundation and FCT grants (\#UID/BIM/04501/2013 and \#PTDC/IMI-IMU/3615/2014). J.P. received a Ph.D. fellowship (\#EDSVS062) from Région PACA and INSERM. The Imaglmm CIML imaging core facility was supported by a grant from France Biolmaging (\#ANR-10-INBS-04-01). Author contributions: J.P., A.M., C.B., A.C., V.C., and A.D. performed the research. J.P., C.B., E.G., and P.P. designed the research and analyzed the data. H.L., L.S., T.-P.V.M., and M.A.S.S. performed gene microrarrays, bioinformatics, and statistical analysis. L. Chasson performed the histology analysis. L. Chiche and N.B. provided lupus patients' serum. J.P., E.G., and P.P. wrote the paper. Competing interests: P.P. and E.G. hold patents on using inhibitors of the PP1/GADD34 complex to treat inflammatory diseases (WO2011061340 A1 EP2503997A1 and US 20120251562). The other authors declare that they have no competing interests. Data and materials availability: Microarray data can be accessed through the GEO repository under accession number GSE90831.

Submitted 19 January 2017

Accepted 21 December 2017

Published 23 January 2018

10.1126/scisignal.aam8104

Citation: J. Perego, A. Mendes, C. Bourbon, V. Camosseto, A. Combes, H. Liu, T.-P. V. Manh, A. Dalet, L. Chasson, L. Spinelli, N. Bardin, L. Chiche, M. A. S. Santos, E. Gatti, P. Pierre, Guanabenz inhibits TLR9 signaling through a pathway that is independent of elF2 $\alpha$ dephosphorylation by the GADD34/PP1C complex. Sci. Signal. 11, eaam8104 (2018). 


\section{ScienceSignaling}

\section{Guanabenz inhibits TLR9 signaling through a pathway that is independent of elF2 $\alpha$ dephosphorylation by the GADD34/PP1c complex}

Jessica Perego, Andreia Mendes, Clarisse Bourbon, Voahirana Camosseto, Alexis Combes, Hong Liu, Thien-Phong Vu Manh, Alexandre Dalet, Lionel Chasson, Lionel Spinelli, Nathalie Bardin, Laurent Chiche, Manuel A. S. Santos, Evelina Gatti and Philippe Pierre

Sci. Signal. 11 (514), eaam8104

DOI: $10.1126 /$ scisignal.aam8104

\section{From fighting hypertension to inflammation}

The FDA-approved antihypertensive drug guanabenz also has anti-inflammatory properties, which are thought to be mediated by the inhibition of GADD34, a phosphatase subunit that promotes the production of proinflammatory cytokines and IFN- $\beta$. Perego et al. found that guanabenz inhibited the activation of TLR9, a receptor that induces type I IFN secretion from immune cells in response to DNA. TLR9 is implicated in autoimmune diseases in which self-DNA is erroneously recognized by the immune system, and guanabenz reduced symptom severity in a mouse model of lupus. However, guanabenz did not inhibit TLR9 by affecting GADD34 activity, but rather by altering cholesterol metabolism such that TLR9 did not reach endosomes where it is fully activated. The authors note that many lupus patients suffer from hypertension and that guanabenz and related compounds could, thus, have dual benefits for these patients.

ARTICLE TOOLS

SUPPLEMENTARY

MATERIALS

RELATED

CONTENT

REFERENCES

PERMISSIONS http://stke.sciencemag.org/content/11/514/eaam8104

http://stke.sciencemag.org/content/suppl/2018/01/19/11.514.eaam8104.DC1

http://stke.sciencemag.org/content/sigtrans/9/456/ra115.full

http://science.sciencemag.org/content/sci/356/6342/eaag3009.full

http://science.sciencemag.org/content/sci/350/6259/455.full

http://stke.sciencemag.org/content/sigtrans/11/528/eaan4144.full

http://stke.sciencemag.org/content/sigtrans/11/551/eaav6248.full

http://immunology.sciencemag.org/content/immunology/2/10/eaag3358.full

This article cites 60 articles, 24 of which you can access for free http://stke.sciencemag.org/content/11/514/eaam8104\#BIBL

http://www.sciencemag.org/help/reprints-and-permissions

Use of this article is subject to the Terms of Service

Science Signaling (ISSN 1937-9145) is published by the American Association for the Advancement of Science, 1200 New York Avenue NW, Washington, DC 20005. The title Science Signaling is a registered trademark of AAAS.

Copyright (C) 2018 The Authors, some rights reserved; exclusive licensee American Association for the Advancement of Science. No claim to original U.S. Government Works 